\title{
Network Search: Climbing the Job Ladder Faster
}

\author{
Marcelo Arbex (University of Windsor) \\ Dennis O'Dea (University of Washington) \\ David Wiczer (Federal Reserve Bank of St. Louis)
}

Working paper $16-06$

Working papers are in draft form. This working paper is distributed for purposes of comment and discussion only. It may not be reproduced without permission of the copyright holder. Copies of working papers are available from the author or at http://ideas.repec.org/s/wis/wpaper.html. 


\title{
Network Search: Climbing the Job Ladder Faster
}

\author{
Marcelo Arbex* \\ David Wiczer
}

August 19, 2016

\begin{abstract}
We introduce a complex network into a search model in which workers find jobs through their network or directly from firms. This framework links heterogeneity in network position to heterogeneity in wage-employment dynamics: better-connected workers climb the job ladder faster, drawing more frequently from the network offer distribution which stochastically dominates the direct-search distribution. The mean-field approach allows a tractable, recursive formulation and our calibrated version is consistent with several empirical findings. Further, we present new evidence consistent with our model: Job-to-job switches use networks more frequently at higher rungs of the ladder.
\end{abstract}

Keywords: Labor Markets; Social networks; Job search; Unemployment; Wages dispersion.

JEL Classification: D83; D85; E24; J31; J64.

*Department of Economics, University of Windsor. arbex@uwindsor.ca.; †Department of Economics, University of Washington. odea@uw.edu; $\ddagger$ Research Division, Federal Reserve Bank of St. Louis. wiczerd@stls.frb.org. We have benefited comments and suggestions from Manolis Galenianos, George-Levi Gayle, Aaron Hedlund, Henry Hyatt, Leo Kaas, Rasmus Lentz, Paulina Restrepo and participants various seminars and conferences. Any errors are our own. 


\section{Introduction}

How do workers find jobs and does it matter? In this paper, we study an equilibrium search model in which some jobs are found through network connections and workers differ in their position within the network. In our framework, jobs found through a searcher's network are fundamentally different from and better than jobs found directly from contact with a firm. The reason is twofold. First, offers passed through network search come from workers who have already selected wages and climbed the ladder - network connections pass along wage offers like their own. The second reason comes from the paradox of friendship, which implies that job referrals come disproportionately from workers who are more central to the network than an average worker. To the extent that workers who are more connected in the network have access to better jobs, they will also refer better jobs to their own connections. This implies that jobs passed through the network generally have higher wages than those found through random search and that workers who find a job through their network generally are better connected. This selection effect again makes jobs found through a network observationally different from those found through direct contact. These model-generated features of network search and labor markets are consistent with well-supported empirical findings.

The heterogeneity presented in our model-workers differ in their network position-implies both differences in workers' finding rates and differences in the distribution from which they sample wage offers. Finding rates differ because better-connected workers have more connections from whom to draw a referral. Thus, differences in network position provide a micro-foundation for finding-rate heterogeneity. But network heterogeneity has another effect: workers at different positions in the network also draw from different offer distributions. A better connected worker samples from a distribution of offers with higher wages. This is because a larger fraction of a wellconnected worker's offers comes from the network rather than direct search. From these outcomes, the model has strong predictions about the differences between a job found via network search and direct search.

Network search, as presented here, is consistent with some of the strongest results in this empirical literature. ${ }^{1}$ In particular, jobs found through a worker's network have (i) higher wages and (ii) longer employment duration and (iii) workers experience shorter unemployment spells. Our model provides a theoretical basis for these findings linking heterogeneity in network connections to wage inequality and differences in employment dynamics. Workers searching through their network have access to a better offer distribution and because those who find a job through their network tend to be better connected, they received offers from this distribution at a higher rate. Employment duration is longer because better matches are higher on the job ladder and naturally last longer. This reasoning is different from that proposed by Dustmann et al. (2015) and many

\footnotetext{
${ }^{1} \mathrm{~A}$ large empirical literature has shown that labor market networks play an important role in matching workers to employers. Even though estimates of the percentage of jobs found through social contacts vary across location and profession, they consistently range between $25 \%$ and $80 \%$ of jobs in a given profession (see, for instance, Holzer (1988), Ioannides and Datcher Loury (2004), Bayer et al. (2008), Hellerstein et al. (2011)).
} 
others, ${ }^{2}$ who attribute these same empirical findings to information frictions. While it may be that offers passed through a network carry better information about match quality, we show that qualitatively similar outcomes do not require information frictions: network heterogeneity is sufficient to generate these empirical findings.

Further, we contribute to the empirical literature by introducing findings from the Survey of Consumer Expectations (SCE) regarding the method of search while on the job. A prediction central to our model is that network search becomes increasingly important at higher rungs of the job ladder. With the SCE, we find direct evidence that higher paid workers are more likely to find their next job via a referral from their network.

Our analytic results underpin each of these relationships to the empirical findings. We first show that the equilibrium wage offer distribution via social networks first-order stochastically dominates the wage offer distribution via direct search. Then it follows that better-connected workers, those who draw more frequently from the network offer distribution, will have higher expected wages. Turning to labor dynamics, we show a higher number of peers also brings more rapid re-employment for the unemployed: well-connected workers receive more referrals and therefore find a new job faster than a worker with fewer peers. After finding the first job, better connected workers are still more likely to find a suitable offer, make a job-to-job change and climb the wage ladder. Changing our perspective, conditional on matching, even at the same wage, if a worker found this job through her network she is more likely to be well connected. We show analytically that the distribution of network links conditional on matching through a network first-order stochastically dominates the distribution of network links for those who match through direct contact.

The tractability of our model comes from our ability to summarize a worker's network position into a scalar state variable, her number of ties. To do so, we employ the mean field approach, which amounts to a set of assumptions over the network and information structure to omit local correlation and neighborhood effects. ${ }^{3}$ With this simplification to the state, we can translate the general form of the equilibrium into an equilibrium we term a "Sufficient Recursive Equilibrium" because it uses a sufficient, scalar statistic to summarize the worker's network position. This allows us to compute and calibrate the model and in this calibrated version we show numerically how better-connected workers climb the job ladder faster, operationalized as the worker's half-life before arriving at the top wage. For each empirical finding, the calibrated version of the model is qualitatively consistent.

Theoretical models of labor market networks generally assume that there are information fric-

\footnotetext{
${ }^{2}$ Many principally empirical papers ascribe their findings, that network search leads to longer-lasting matches at higher wages, to network connections ameliorating information frictions. See Granovetter (1995); Kugler (2003); Datcher (1983); Marmaros and Sacerdote (2002); Simon and Warner (1992)

${ }^{3}$ The mean field approach is a technique to analyze the long run or average behavior of a complex system and it was first developed for use in statistical physics to analyze the Ising model of interacting charged particles (see Vega-Redondo (2007) for a summary). By replacing the effect of nearby particles with the "average" effect of the magnetic field, one can solve for the equilibrium field, without needing to consider the potentially intractable interaction of local effects.
} 
tions that hinder the job search behavior of unemployed workers and/or firms, and that information flows through networks. In models such as Calvo-Armengol and Jackson (2007) and Ioannides and Soetevent (2006) job searchers can learn about job vacancies either directly from employers or indirectly via employed individuals among their network contacts, but unemployed workers do not have full information about job vacancies. In equilibrium, better-connected job searchers are more likely to find employment and to have higher wages. In Montgomery (1991), the information imperfection is on the employer side. Employers do not have full information about the quality of job applicants and firms learn about a potential worker's ability if the firm employs individuals from the potential worker's network. In equilibrium, individuals are more likely to receive and accept wage offers from businesses that employ others in their network. Fontaine (2008) presents a matching model à la Pissarides (2000) where wage dispersion arises endogenously as the consequence of the joined dynamics of networks, firms' strategies and wage bargaining.

From the search literature, this paper is directly related to the equilibrium on-the-job search models in the vein of Burdett and Mortensen (1998). being qualitatively consistent with earnings dispersion, search frictions alone have difficulty generating realistic earnings heterogeneity (Hornstein et al. (2011) and Mortensen and Pissarides (1999)). Worker and employer heterogeneity, however, can explain the observed shape of earning distributions (van den Berg and Ridder (1998); Bontemps et al. (2000); Postel-Vinay and Robin (2002)). In this thread, our model introduces a dimension of unobserved heterogeneity that increases wage dispersion among observationally identical workers.

Several very relevant papers consider the contribution of network search to inequality. Mortensen and Vishwanath (1994) considers a Burdett and Mortensen (1998) model but in which sometimes a worker draws from the earnings rather than the offer distribution. Our concept of a referral is also a draw from the earnings distribution, however by adding an irregular network we show how network draws are actually from a different weighting to the earnings distribution because one's peers are not representative of the whole population. In other words, our structure shows how network search adds another layer of inequality on top of that in Mortensen and Vishwanath (1994). Galenianos (2014) presents a search model with job referrals through a network and rich predictions about business cycle fluctuations and cross-sector differences in measured vacancy yield. In it, networks also contribute to inequality and worker dynamics depend on the network. But unlike our work, he considers a homogeneous network, so differences in network location cannot contribute to wage dispersion. ${ }^{4}$

A great deal of empirical literature has studied the role networks play, and we see their findings largely consistent with our model's implications. Here we briefly summarize some of the empirical support for network search leading to (i) higher wages, (ii) longer employment duration, and (iii)

\footnotetext{
${ }^{4}$ New work in Galenianos (2016) is also quite relevant. In this paper, the network structure is endogenous and ex ante differences in types makes some more desirable connections than others This type of worker becomes more central and the endogenous structure exacerbates inequality.
} 
shorter unemployment spells. Using a direct measure of network quality based on the employment status of close friends, Cappellari and Tatsiramos (2015) provide robust evidence that a higher number of employed contacts increases wages for high-skilled workers forming networks with nonfamilial contacts. Bentolila et al. (2010) analyze surveys from both the US and Europe including information on job finding through contacts and find that network contacts reduce unemployment duration by 1-3 months on average. Hellerstein et al. (2015) present evidence that workers who are more residentially networked to their co-workers at the time of hire have lower rates of turnover. They also provide evidence that labor market network strength is linked to more rapid re-employment and re-employment at neighbors' employers. Defining networks by "co-displaced" workers, Cingano and Rosolia (2012) present evidence for Italy that employment (re-employment) of other co-displaced workers in the network reduces unemployment duration. There are related papers that study the effect of coworker-based networks and employee's referrals on individual labor market outcomes (see Brown et al. (2013), Glitz (2013), and Burks et al. (2015))

Our contribution is to incorporate irregular networks into the search and matching process. In particular, by acknowledging the role of heterogeneity in network connections we provide one reason that workers are not equally likely to locate an opening nor will they find the same quality of job. We believe that this paper provides a framework to analyze wage dispersion and unemployment as driven by (non-observable) worker heterogeneity in social connections. The paper proceeds as follows. Section 2 presents a model of labor markets with two channels of information about job opportunities: direct search and social networks. In Section 3, we discuss the steady-state equilibrium and the associated distributions; in Section 4, we show that the earnings distribution of a peer stochastically dominates the earnings distribution in the economy. Section 5 presents the results from a calibrated version of our model and we use the model to explore and discuss some empirical results about network search and job finding through labor market networks. Section 7 offers concluding comments.

\section{A Model of Search and Networks in Labor Markets}

\subsection{Demography and Network Structure}

There are large fixed numbers of workers and employers participating in the labor market, formally a continuum of each. The measure of workers is normalized to one. At a moment in time, each worker is either unemployed (state $i=0$ ) or employed (state $i=1$ ). Workers learn about job opportunities at rates $\lambda^{0}$ when unemployed and $\lambda^{1}$ when employed. Job information is acquired through either direct search or a worker's social network. Job information arriving directly from employers depends on a worker's current employment state. Let $\gamma^{i}$ denote the arrival rate of direct offers while a worker is currently in state $i \in\{0,1\}$. These offers are drawn from a firm offer distribution $F(w)$. 
Job offer information can also be acquired through a worker's social network. A network is a collection of nodes and edges, where each worker is a node, and an edge exists between two workers if job information may pass between them. The number of edges a node has is called its degree. In general, networks may be very complex, ranging from highly structured to highly random. One way to describe a network is its degree distribution, which gives the proportion of nodes that have each possible degree. Thus, each worker has peers to whom they are connected in a social network and this summarizes her type, the crucial dimension of heterogeneity.

To clarify notation, we will refer to this quantity with several variable names depending on the role of the worker when we refer to her. When we use $z$ to denote her number of peers, the worker is a generic agent. When we denote the type as $s$ it will refer to a peer, and type $t$ will refer to an employee. The network may be described by the degree distribution $\Omega(z)$ and we will focus on large, complex networks, so that $z \in[1, \infty) .^{5}$

We do not assume any particular degree distribution for our results; it may be finite or continuous, and our results apply to arbitrary degree distributions. We require, however, that the network described by the degree distribution be complex, in the following sense: workers must not be able to infer too much information about the network and their peers from their own position in the network. The following example illustrates this requirement. Consider a highly structured network in which all workers are part of dense clusters of 6 workers, connected to each one of 5 peers. Two of these 6 peers have a connection to another dense cluster of 6 agents, and this continues ad infinitum. This may be visualized as clusters on a line, as in Figure 1. Such a network has a discrete degree distribution; all workers will have either five or six peers, with the proportion of workers of type 6 being $\frac{2}{6}$.

Knowing one's own type, therefore, conveys a great deal of information; a worker of type 5 knows that he is not one of the "bridge" workers, and thus knows that each of his 5 peers is connected to one another, and two will be bridges. Thus he may infer that their employment statuses will be highly correlated, and with a long enough memory, he may learn which peers of his are bridges. A worker of type 6 knows he is a bridge, and thus knows 5 of his peers are in a dense cluster - one of whom is also a bridge - and one is in separate cluster, and may eventually learn which.

Contrast this with a different network structure, constructed as follows: starting with a single worker, endow this worker with either 5 or 6 peers, choosing 6 with probability $\frac{2}{6}$. For each of this worker's peers, endow them with either 4 or 5 peers, choosing 5 with probability $\frac{2}{6}$, ad infinitum. This network may be visualized as a random tree, that continues forever, as in Figure 2. This network shares the same degree distribution as the former network, but workers cannot infer anything from their own type; the types of their peers are independent of each other and

\footnotetext{
${ }^{5}$ This is common to approximate the discrete number of network connections with a continuous variable, so rather than $z \in 1, \ldots, \infty$ we write this as a half-closed interval. We could equally constrain ourselves to write this as discrete distribution with finitely many types.
} 


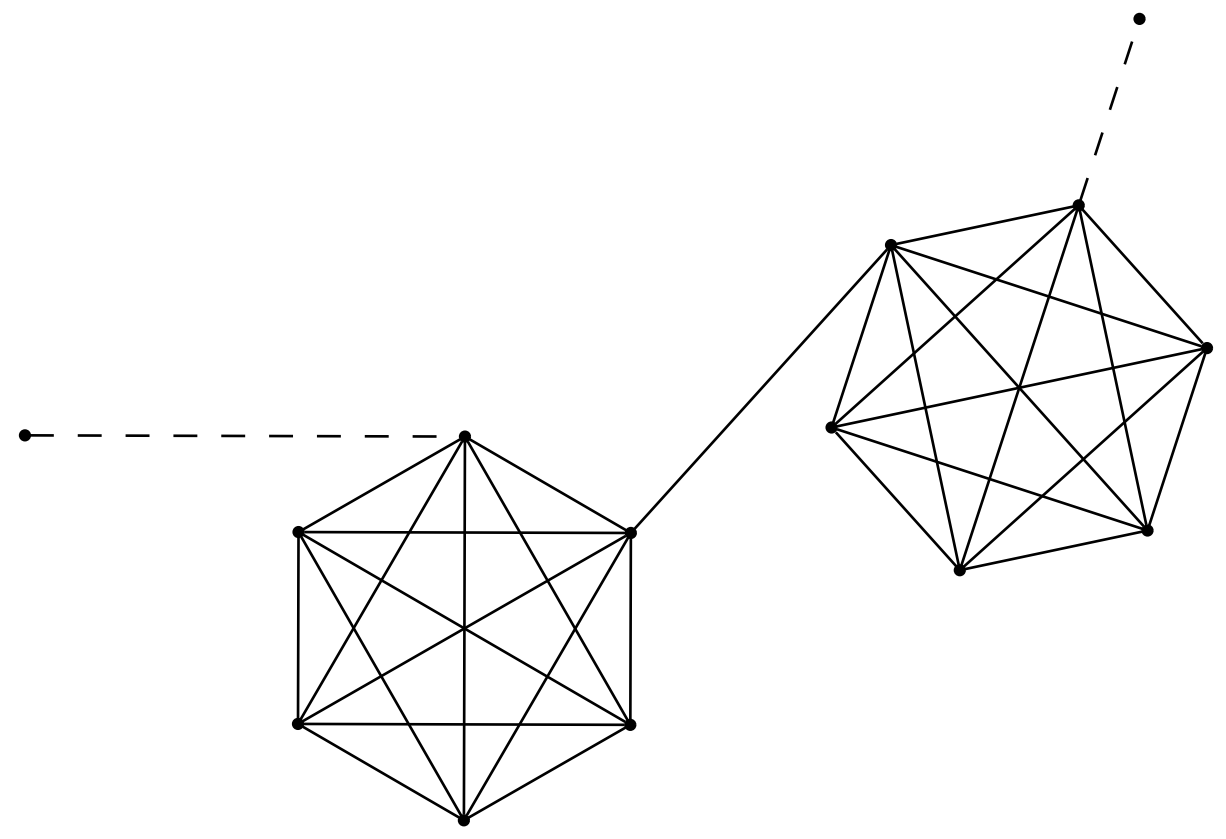

Figure 1: A highly structured network

uncorrelated. This network is more complex, and is the type of network we consider.

Our approach relies on three key assumptions. First, we consider random, complex networks; that is, rather than model worker behavior when the network's structure is known with perfect information, we consider agents who believe the social network they inhabit was generated by the so-called "configuration" model. This is a very general process introduced by Bender and Canfield (1978). We follow the formulation of Chung and $\mathrm{Lu}(2002) .{ }^{6}$ This procedure can generate large, complex networks with arbitrary degree distributions.

It works as follows: for a fixed number $n$ of nodes, fix a desired degree distribution $\Omega(z)$. Assign to each note $i$ weight $\Omega(i)$. For each pair of nodes $i j$, form a link between them at random, with probability proportional to $\Omega(i) \Omega(j)$. This procedure, as $n$ rises, will generate a large, complex network with the desired degree distribution. Networks generated by this process are almost all trees, in that there is no local structure. To put this concretely, the probability a worker's peers are themselves peers vanishes and there are no correlations between node properties; a node of degree $j$ is no more likely to be connected to nodes of one type than another; the degree distribution of a neighbor is the same for every neighbor, for every node. For this collection of random networks, nothing can be inferred about a worker's global position in the network from their own degree $z$.

Next, we rely on two informational assumptions. The second assumption is that we assume a worker cannot observe their peer's status: neither their degree, their employment status, nor their wage. Under this assumption, workers must infer the status of their peers. Our final assumption, that of limited memory, ensures that this inference can be based only on global averages. By assuming workers cannot recall the sequence of job offers and associated wages from their peers,

\footnotetext{
${ }^{6}$ For further details, see Vega-Redondo 2007
} 


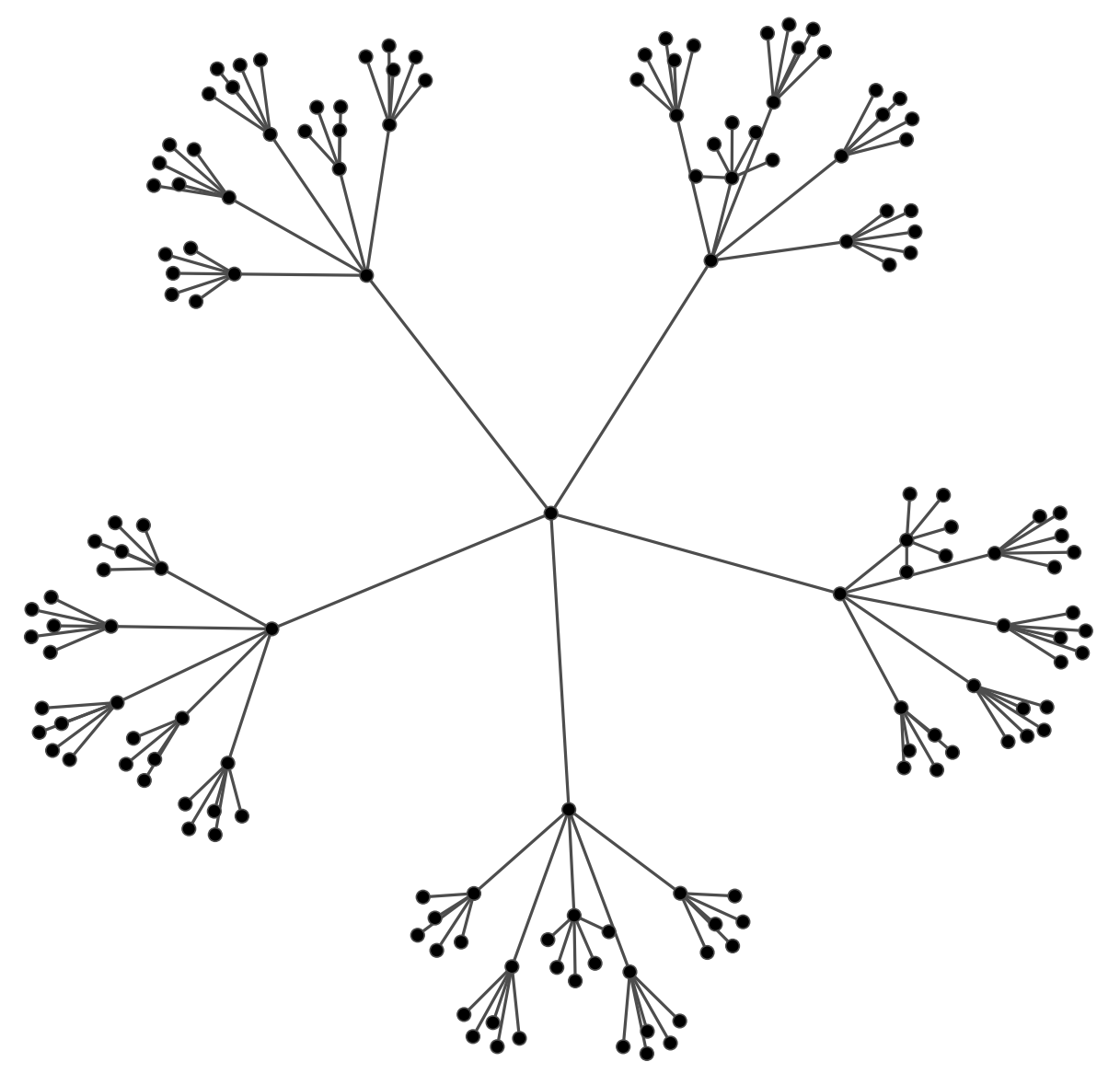

Figure 2: A random tree network

they can only use the degree distribution and average employment status to form a belief about the value of a job passed from a peer.

In our numerical applications, we assume power-law distributions. The networks we consider have finite average degree but unbounded variance, indicating the presence of extremely high degree nodes. Numerous empirical networks have been observed to be well described by these power-law networks, in which the number of nodes of degree $z$ is proportional to $\frac{1}{z^{\alpha}}$ for some $\alpha$ (Vega-Redondo (2007), Newman (2004))

\subsection{Job and Offer Flows}

Under these assumptions, it is correct to use the mean field approach, replacing idiosyncratic local effects with "expected" average effects. This is discussed in more detail in Appendix 8.6. In this section we will use this approach to characterize the search technology in which network and direct search co-exist. This structure allows us to characterize worker types simply by their number of links, and so the rest of the objects we introduce treat this scalar quantity as the dimension on which workers are heterogeneous, sufficient to represent the worker's position in the network.

$G(w, z)$ is the earnings distribution among agents with $z$ links, or in other words, the proportion 
of employed workers of type $z$ earning a wage no greater than $w$. The wage distribution in the population and the earnings distribution of a worker's peers are defined as, respectively,

$$
\begin{aligned}
& G(w) \doteq \int_{z} \Omega(z) G(w, z) d z \\
& \tilde{G}(w) \doteq \int_{s} \Psi(s) G(w, s) d s,
\end{aligned}
$$

where $\Psi(s)$ is the probability a worker's peer has $s$ peers herself. A job offer learned via an unemployed worker's network is, therefore, a random draw from the endogenous earnings distribution $\tilde{G}(w)$ of a random peer. Note that $\Psi(s) \neq \Omega(s)$, i.e., the probability one of your peers has $s$ links is not equal to the proportion of workers who have $s$ links. This is sometimes called the paradox of friendship: a very general phenomenon of networks identified by Feld (1991), implying that your friends are likely to have more friends than you. This is because agents with many peers, and a large type $s$, are disproportionately likely to be your peers. The distribution over peer types is given by $\Psi(s)=s \Omega(s) /\langle z\rangle$, where $\langle z\rangle=\int_{z=1}^{\infty} z \Omega(z) d z$ is the average degree in the network. This peer is employed herself with probability $n(s)$, the employment rate of workers of type $s$. The job offer she passes along will be accepted if it is above the reservation wage of the worker.

The probability a worker of type $z$ in state $i$ receives an offer via a peer in her social network is

$$
\rho^{i}(z)=\left(1-\left[1-\int_{s} \Psi(s) n^{*}(s) \gamma^{1} \frac{\nu^{i}}{s} d s\right]^{z}\right)
$$

where $\nu^{i} / s$ is the probability at which job information is passed along and $n^{*}(s)$ is the steady-state employment rate in the economy of type $s$ peers. We assume that jobs are passed to state $i$ workers in a network at a constant and equal rate. If one of an agent's peers has an offer to pass, each of her $s$ other peers are equally likely to receive her job information. This means that, the greater $s$, the more competition for this job information there is and the more unlikely this job is to be passed to a particular peer. The arrival rate $\gamma^{1}$ appears because jobs to be passed are acquired in the same way as on-the-job search where the peer is searching for her peers rather than herself.

From here we can see already that heterogeneity in $z$ implies heterogeneity in job finding rates. The density of the network affects the finding rate in two ways. A job offer to be passed arrives at rate $\gamma^{1} \nu^{i}$ but is multiplied by $\frac{1}{s}$ because every one of the peer's connections entails more competition with other workers connected to the same individual. On the other hand, if the network is denser and searching workers have more connections $z$, they have more chances to get an offer and hence faster finding rates. Note also that mean field approach has already appeared, because we integrate over the distribution of peers' connectedness $\Psi(s)$, rather than knowing the 
actual number of connections any of a searcher's peers have.

The probability $\nu$ can be interpreted as a "socializing" parameter, representing how strongly tied to one another peers in this network are and, hence, how likely they are to pass along a potential job. We will assume that $\nu^{0} \geq \nu^{1}$, i.e., ties are stronger and jobs are more likely to be passed to peers who are unemployed. Alternatively, this can be interpreted as there being less effort devoted to social job search activities when employed and, hence, weaker social ties. ${ }^{7}$

Integrating over all possible peer types $s$, we obtain the weighted distribution of all acceptable offers received by a type $z$ worker. Or, in other words, the density of wages among peers is defined as follows:

$$
\theta(w)=\int_{s} \Psi(s) \frac{\partial G(w, s)}{\partial w} d s
$$

Depending on a worker's employment status, she receives job offers, either directly or through her social network, at a rate

$$
\lambda^{i}=\gamma^{i}+\left(1-\gamma^{i}\right) \rho^{i}(z)
$$

We assume that workers do not know the employment status of their peers (so that the expectation above includes $n(s)$, the probability their peers are employed) nor the exact wages their peers earn. Hence, the average employment rate in the economy $N$ will depend on each of these variables, as well as on the job separation rate $\delta$, the job arrival rate $\gamma^{i}$ and the network $\Omega(z)$.

\subsection{Job Search and Wage Posting with Labor Market Networks}

In this section we will describe the problem of households and firms in the presence of the network structure described above. In many ways, the frictional labor market we present is similar to that of Burdett and Mortensen (1998) with heterogeneous workers. The crucial difference is that this heterogeneity has a very particular structure that affects job finding rates, the distribution from which wages are drawn and firms' recruiting.

Jobs are identical except for the posted wage associated with them; productivity is the same. A job offer represents a new position at a firm. Employed workers can hear about new positions either at their own firms or at other firms. In the first case, the employed worker passes the job information to her peers. This new job is identical to the job of the employed worker, so that the worker who hears of it will not have any interest in taking the offer himself. Hence, this is a model of referral. An employed worker can only refer direct connections to jobs in her own firm. This relatively simple transmission process precludes a multi-step job transmission and simplifies our analysis. We focus instead on the role of the structure of the social network, rather than the

\footnotetext{
${ }^{7}$ This approach follows Calvo-Armengol and Jackson (2004). In words, the probability one of your peers passes you job information depends on the job arrival rate, the socializing parameter $\nu$, the average employment rate $n$, and the average degree in the network $\langle z\rangle$. This captures both the benefit of there being highly connected peers and the cost of more competition for this information. More-connected peers are likely to be employed and thus pass information but they also have more potential recipients.
} 
technology of the transmission process. Rather than passing along the referral, employed workers can also move from lower- to higher-paying jobs if they find an offer from a higher-paying job.

All job offers stand for one period only. If a job offer is declined, it expires and the position is lost. Hence, referrals also last only one period, during which they are instantly transmitted to other workers. Because search is random, each of those postings may be filled by a currently employed or an unemployed worker.

The principal decisions in the model are the reservation wage of the worker and the posted wage of the firm. On the worker side, the crucial heterogeneity is their position in the network, which is summarized by their number of connections $z \in[1, \infty)$. For firms, their posted wage offers may be filled by any type of worker: employed or unemployed, well connected or isolated. These wages exist in a compact subset of the reals, which we denote as $\mathbb{W} \subset \mathbb{R}_{+}$. As we present their problems, note that although there is potentially a great deal of heterogeneity across workers based on their position in the network, it can be summarized completely by $z$. This feature, which is crucial to the tractability of our model, is revisited in Appendix 8.6.

\subsection{Households}

The state of the unemployed worker is her number of connections $z \in[1, \infty)$ and the state of an employed worker is $(z, w) \in[1, \infty) \times \mathbb{W}$.

To calculate value functions, we use the mean field approximation of the network structure. This approach assumes the global state of the network is replicated locally and that there are no neighborhood effects. Under that Chang-Lu network topology, this assumption is correct: due to limited memory and incomplete information, workers cannot infer anything from their own history of job matches about the employment status or type of their neighbors. They must form expectations using the type distribution to calculate continuation values for jobs passed from each peer, and each peer is simply a further possible source of job information.

One view of this assumption is to consider the economy already in the steady state; in such an economy, each peer is identical and without knowledge of the global structure of the network, and each worker can use only the type distribution to form expectations. This assumption of homogeneous mixing replaces the idiosyncratic effect of each worker's peers with the average effect of a peer.

Given the distribution of offers obtained through direct contact, $F$, and the distribution of earnings that may be referred, $G$, the value function of an unemployed worker of type $z$ is

$$
\begin{aligned}
r V^{0}(z) & =b+\gamma^{0}\left\{\int_{R(z)}^{\bar{w}}\left[V^{1}(z, x)-V^{0}(z)\right] d F(x)\right\} \\
& +\left(1-\gamma^{0}\right) \rho^{0}(z) \int_{R(z)}^{\bar{w}}\left[\int_{s} \Psi(s) \frac{\partial G(w, s)}{\partial w}\left(V^{1}(z, w)-V^{0}(z)\right) d s\right] d w
\end{aligned}
$$


where $r$ is the economy's interest rate. In words, the value of an unemployed worker with $z$ peers is the unemployment benefit, the expected value of hearing about a job directly, plus the expected value of hearing about a job from a peer.

Again taking $F$ and $G$ as given, the value function of an employed worker with $z$ connections and wage $w$ is

$$
\begin{aligned}
r V^{1}(z, w) & =w+\delta\left[V^{0}(z)-V^{1}(z, w)\right]+\gamma^{1}\left\{\int_{w}^{\bar{w}}\left[V^{1}(z, x)-V^{1}(z, w)\right] d F(x)\right\} \\
& +\left(1-\gamma^{1}\right) \rho^{1}(z) \int_{w}^{\bar{w}}\left[\int_{s} \Psi(s) \frac{\partial G(x, s)}{\partial x}\left(V^{1}(z, x)-V^{1}(z, w)\right) d s\right] d x .
\end{aligned}
$$

That is, the expected discounted lifetime income of a worker currently employed, with $z$ peers in her network, is her wage $w$ plus the expected value of becoming unemployed plus the expected value of hearing of a better job either directly from firms or through her social network. Her job-search policy is simple, so we plugged into the value function in equation 7: she takes any job offering wages greater than her current wage $w$.

Given an offer $w$, an unemployed worker will accept it if it is higher than her reservation $R(z)$, which may endogenously depend on peers, $z$. If unemployed, the worker receives unemployment benefits $b$. At the reservation wage $R(z)$, we have that $V^{1}(z, R(z))=V^{0}(z)$. Plugging $w=R(z)$ into equation (7) and using equation (6), we obtain

$$
\begin{aligned}
R(z)-b & =\left(\gamma^{0}-\gamma^{1}\right)\left\{\int_{R(z)}^{\bar{w}}\left[V^{1}(z, x)-V^{0}(z)\right] d F(x)\right\} \\
& +\left[\left(1-\gamma^{0}\right) \rho^{0}(z)-\left(1-\gamma^{1}\right) \rho^{1}(z)\right]\left\{\int_{R(z)}^{\bar{w}}\left[\int_{s} \Psi(s) \frac{\partial G(x, s)}{\partial x}\left(V^{1}(z, x)-V^{1}(w, z)\right) d s\right] d x\right\} \\
& =\left(\gamma^{0}-\gamma^{1}\right)\left\{\int_{R(z)}^{\bar{w}} V_{x}^{1}(z, x)[1-F(x)] d x\right\} \\
& +\left[\left(1-\gamma^{0}\right) \rho^{0}(z)-\left(1-\gamma^{1}\right) \rho^{1}(z)\right]\left\{\int_{R(z)}^{\bar{w}} V_{x}^{1}(z, x)(1-\tilde{G}(x)) d x\right\}
\end{aligned}
$$

where the derivative $V_{x}^{1}(z, x)$, using equation (7), is given by:

$$
V_{x}^{1}(z, x)=\left[r+\delta+\gamma^{1}(1-F(x))+\left(1-\gamma^{1}\right) \rho^{1}(z)(1-\tilde{G}(x))\right]^{-1}
$$

The law of motion of the employment rate of a worker with $z$ peers, $n(z)$, is

$$
n_{t+1}(z)=(1-\delta) n_{t}(z)+\left[1-n_{t}(z)\right]\left\{\gamma^{0}\left[1-F\left(R_{t}(z)\right)\right]+\left(1-\gamma^{0}\right) \rho^{0}(z)\left(1-\tilde{G}\left(R_{t}(z)\right)\right)\right\}
$$

In the steady state, $n_{t+1}(z)=n_{t}(z) \doteq n^{*}(z)$ and, as in Burdett and Mortensen (1998), we set 
$r=0$. Hence, the employment rate of such workers is:

$$
n^{*}(z)=\frac{\gamma^{0}[1-F(R(z))]+\left(1-\gamma^{0}\right) \rho^{0}(z)\left(1-\tilde{G}\left(R_{t}(z)\right)\right)}{\delta+\gamma^{0}[1-F(R(z))]+\left(1-\gamma^{0}\right) \rho^{0}(z)\left(1-\tilde{G}\left(R_{t}(z)\right)\right)},
$$

and the economy's employment rate is given by

$$
N^{*}=\int_{z} n^{*}(z) \Omega(z) d z .
$$

From the steady-state allocation of matches at each $z$, the number of employed workers receiving a wage no greater than $w$ at time $t, G(w, z) n(z)$, can be calculated. Its time derivative can be written as follows:

$$
\begin{aligned}
\frac{\partial G(w, z) n(z)}{\partial t} & =\left[1-n^{*}(z)\right]\left[\gamma^{0} \max \{F(w)-F(R(z)), 0\}\right] \\
& +\left[1-n^{*}(z)\right]\left[\left(1-\gamma^{0}\right) \rho^{0}(z)\{\tilde{G}(w)-\tilde{G}(R(z))\}\right] \\
& -n^{*}(z) G(w, z)\left\{\delta+\gamma^{1}[1-F(w)]+\left(1-\gamma^{1}\right) \rho^{1}(z)(1-\tilde{G}(w))\right\} .
\end{aligned}
$$

Consider a given wage $w \geq R(z)$, which holds for any accepted wage $w$. In a steady state, $\partial[G(w, z) n(z)] / \partial t=0$, and using equation (13) to implicitly define $G(w, z)$, we obtain:

$$
G(w, z)=\frac{\left[1-n^{*}(z)\right]\left\{\gamma^{0}[F(w)-F(R(z))]+\left(1-\gamma^{0}\right) \rho^{0}(z)\{\tilde{G}(w)-\tilde{G}(R(z))\}\right\}}{n^{*}(z)\left[\delta+\gamma^{1}[1-F(w)]+\left(1-\gamma^{1}\right) \rho^{1}(z)(1-\tilde{G}(w)]\right.}
$$

From equations (11) and (14), the steady-state distribution of wages earned by employed workers with $z$ links is written as

$$
\begin{aligned}
G(w, z) & =\delta\left\{\frac{\gamma^{0}[F(w)-F(R(z))]+\left(1-\gamma^{0}\right) \rho^{0}(z)[\tilde{G}(w)-\tilde{G}(R(z))]}{\delta+\gamma^{1}[1-F(w)]+\left(1-\gamma^{1}\right) \rho^{1}(z)[1-\tilde{G}(w)]}\right\} \\
& \left\{\gamma^{0}[1-F(R(z))]+\left(1-\gamma^{0}\right) \rho^{0}(z)[1-\tilde{G}(R(z))]\right\}^{-1}
\end{aligned}
$$

On the labor demand side, we will denote the average size of a firm whose employees have $t$ links and get paid a wage $w$ as $l(w, t)$. Since there is a range of workers with different numbers of employed peers $t \in[1, \infty)$ who will earn a wage $w$, the total labor input per firm at this particular wage is given by 


$$
L(w)=\int_{t} l(w, t) d t
$$

An employer's steady-state profit, given the wage offer $w$, can be written as $\pi=(p-w) L(w)$, where $p$ denotes the flow of revenue generated per employed worker. Finally, an employer's problem is to choose the optimal wage that maximizes its steady-state profit flow, i.e.,

$$
\pi=\max _{w}(p-w) L(w) .
$$

\section{The Steady-State Equilibrium}

We now discuss the steady-state equilibrium and the associated distributions. An equilibrium solution to the search and network labor market economy is a household solution, $V^{0}(z), V^{1}(z, w)$ and $R(z)$ along with optimizing firm behavior which implies a wage offer distribution $F(w)$, such that every wage in the support of $F(w)$ is associated with the same profit $\pi$, and both sides of the market are consistent with the definitions of $G(w, z), n(\mathrm{z})$. We make this formal in the definition of the Sufficient Recursive Equilibrium. We call this equilibrium concept "sufficient" because it is defined using $z$, the number of peers to whom a worker is connected in a social network, as a sufficient statistic for the worker's position in the network. The more general equilibrium, in which the worker's network state is given by a much more complicated object which we call $\chi$ is described in Appendix 8. There, we prove that our framework exploits the mean-field approach to reduce the meaningful heterogeneity to $z$.

Definition 1. A Sufficient Recursive Equilibrium is the unemployed searcher's value function $V^{0}:[1, \infty) \rightarrow \mathbb{R}$, the worker's value function $V^{1}:[1, \infty) \times \mathbb{W} \rightarrow \mathbb{R}$ and reservation wage $R$ : $[1, \infty) \rightarrow \mathbb{R}$, a level of profit at each posted wage $\pi: \mathbb{W} \rightarrow \mathbb{R}_{+}$, a distribution of posted wage offers $F: \mathbb{W} \rightarrow[0,1]$, distributions of workers' wages $G: \mathbb{W} \times[1, \infty) \rightarrow[0,1]$ and employment distribution $n:[1, \infty) \rightarrow[0,1]$, such that

- $V^{0}, V^{1}$ and $R$ satisfy equations (6), (7) and (8), respectively,

- $G$ and $n$ are consistent with equations (14) and (11) and

- $F$ implies that $\pi=\bar{\pi} \forall w \in \mathbb{W}$, where $\pi$ is given by equation (17).

The principal task of solving for an equilibrium is now to find the distribution, $F$, for posted wages that is consistent with equal profits. To do so, we will first solve for $L(w)$, an object implied both by the wages posted in $F$ and the recruitment and loss of workers through network search.

First looking at outflows, a firm offering wage $w$ will lose workers to unemployment at the exogenous separation rate $\delta$. Workers at this firm will be directly contacted by other firms at rate 
$\gamma^{1}$, and the probability the firm they are contacted by offers a wage above $w$ is $1-F(w)$. Workers at this firm are contacted by their peers at rate $\left(1-\gamma^{1}\right)$, and these peers will communicate a job offer at a firm with a wage above $w$ with probability $\rho^{1}(z)(1-\tilde{G}(w))$, which gives the probability an acceptable job offer is passed to that worker. Hence, we define the separation rate $\beta(w, z)$ to be the sum of these terms:

$$
\beta(w, z)=\delta+\gamma^{1}[1-F(w)]+\left(1-\gamma^{1}\right) \rho^{1}(z)(1-\tilde{G}(w))
$$

and the mass of workers of type $z$ leaving the firm is thus $l(w, z) \beta(w, z)$.

Consider now recruiting to this firm. First, there is a flow of recruits via direct contact. Unemployed and employed workers are contacted directly by firms at rate $\gamma^{0}$ and $\gamma^{1}$, respectively. These job contacts are spread among the $\frac{1}{M}$ firms, and they will result in jobs for the unemployed (employed) if the offered wage is above their reservation wage (current wage).

In our economy, there are $\Omega(z)(1-n(z)) \mathbb{I}_{R(z) \leq w}$ workers of type $z$ that may be recruited from unemployment at wage $w$ where $\mathbb{I}_{R(z) \leq w}=1$ if $R(z) \leq w$ and zero otherwise. There are also $\Omega(z) n(z) G(w, z)$ employed workers of type $z$ earning less than $w$ who may be recruited by this employer. Direct recruiting is therefore given by

$$
\frac{\Omega(z)}{M}\left\{[1-n(z)] \gamma^{0} \mathbb{I}_{R(z) \leq w}+n(z) \gamma^{1} G(w, z)\right\} .
$$

Recruiting also occurs indirectly through the social network of a firm's employees. A firm offering wage $w$ employs $L(w)$ workers. It is the peers of these workers who may be recruited. Consider an employed worker of type $t$ at this firm, which employs $l(w, t)$ such workers. An employed worker contacts all $t$ of her peers about job opportunities at her own firm. The total amount of possible referrals made by these workers is $l(w, t) t$, i.e., the more connections employees have, the more referrals they will make. These peers can be either employed or unemployed and may have different number of peers themselves.

Consider a given worker who is contacted by her employed peer. With probability $\Psi(z)$ she is of type $z$. With probability $1-n(z)$ she is unemployed. With probability $\nu^{0}$ the job offer is transmitted, and it will be accepted if the wage is above her reservation wage $R(z)$. On the other hand, with probability $n(z)$, the worker contacted is employed. The job offer is then transmitted with probability $\nu^{1}$, and it will be accepted if the wage is above her current wage, which happens with probability $G(w, z)$. Thus, the indirect recruiting of workers of type $z$ by employees of type $t$ of a firm paying $w$ is given by

$$
\gamma^{1} \ell(w, t) \Psi(z)\left\{(1-n(z)) \mathbb{I}_{R(z)<w} \nu^{0}+n(z) G(w, z) \nu^{1}\right\} .
$$

Integrating this over $t$, we get the total volume of (indirect) recruiting of workers of type $z$ from 
all the firm's current employees, i.e.,

$$
\int_{t} \gamma^{1} l(w, t) \Psi(z)\left\{[1-n(z)] \nu^{0} \mathbb{I}_{R(z) \leq w}+n(z) \nu^{1} G(w, z)\right\} d t
$$

Note that unlike direct recruiting, indirect contacts are not spread among the $M$ active firms. These indirect contacts are in a sense "targeted," since the job information being spread by a firm's employees is about job opportunities in that firm only. The term $l(w, t)$ reflects how the firms' current employees are not only valuable because of their productivity $p$, they are also valuable in how they can recruit others. The labor force is, in this sense, the firms' search capital. These referrals are not distributed representatively, however. From the perspective of the type $z$ worker who will get the referral, this employed worker is her connection. As already described, this implies that the employed worker is expected to be better-connected than average. connections are distributed by $\Psi(\cdot)$, meaning she passes referrals to more connected workers.

Combining (19) and (20), the total hiring $h(w, z)$ of workers of type $z$ by a firm paying $w$ is thus

$$
\begin{aligned}
h(w, z) \equiv & \frac{\Omega(z)}{M}\left\{[1-n(z)] \gamma^{0} \mathbb{I}_{R(z) \leq w}+n(z) \gamma^{1} G(w, z)\right\} \\
& +\int_{t=1}^{\infty} \gamma^{1} \times \ell(w, t) \Psi(z)\left\{(1-n(z)) \mathbb{I}_{R(z)<w} \nu^{0}+n(z) G(w, z) \nu^{1}\right\} d t
\end{aligned}
$$

In the steady state, the flow of workers of type $z$ leaving this firm, equation (18), must equal the flow of workers of type $z$ entering this firm, equation (21), and we must have

$$
l(w, z) \beta(w, z)=h(w, z)
$$

Notice that the steady-state condition, equation (22), represents the balanced (separation and recruiting) flows of workers, with $z$ peers, for a particular firm offering wage $w$. If $w$ is below $R(z)$, no workers of this type will be recruited to this firm from unemployment. If there are no workers of type $z$ currently earning less than $w$, then $G(w, z)=0$ and no workers of this type will be recruited to this firm from other firms. The steady state level of employment of this type of worker, at this firm, will then be zero - the wage $w$ may not be high enough to attract workers of this type if they have better opportunities. Notice however that this is an equilibrium phenomenon and depends on both $R(w)$ and $G(w, z)$.

The equilibrium measure of workers of type $z$ earning a wage $w$ is either 0 , if $w<R(z)$, or

$$
l(w, z)=\frac{h(w, z)}{\beta(w, z)}
$$

A firm offering wage $w$ will attract workers of many different types. Let $\hat{z}$ be the type of worker whose reservation wage is equal to $w$, i.e., $R(\hat{z})=w$. Due to monotonicity of $R(z)$, workers with 
type $z \leq \hat{z}$ will accept $w$, since $R(\hat{z})=w$, while workers of type $z>\hat{z}$ will not. Hence, the firm's total labor force is given by

$$
L(w)=\int_{z=1}^{\hat{z}} \frac{h(w, z)}{\beta(w, z)} d z
$$

Let $R(1)$ be the reservation wage of the lowest type, that is, the reservation wage of workers with only one peer in their network. The employer offering the lowest wage in the market - the infimum $\underline{w}$ of the support of an equilibrium $F$-will maximize its profit if and only if $\underline{w}=R(1)$ and it will employ a labor force of

$$
L(\underline{w})=L(R(1))=\frac{h(R(1), 1)}{\beta(R(1), 1)}=\frac{\frac{\Omega(1)}{M} \gamma^{0}(1-n(1))}{\delta+\gamma^{1}+\left(1-\gamma^{1}\right) \rho^{1}(z)(1-\tilde{G}(R(1)))},
$$

where $h(R(1), 1)$ is the flow of recruits to this firm and $\beta(R(1), 1)$ is a measure of workers of type $z=1$ leaving the firm (separation rate). Notice that the only type of worker this firm hires is $z=1$. Furthermore, this firm does not recruit from other firms, because any employed workers are already earning at least $\underline{w}$.

At the top of the wage distribution, the separation rate for a firm offering $\bar{w}$ is simply $\delta$, i.e., $\beta(\bar{w}, z)=\delta$. Firms paying the highest wage in equilibrium will lose workers only to unemployment, not to other firms. On the hiring side, however, this firm recruits directly or indirectly all types of workers from all other firms as well as from the unemployment pool. Since $F(\bar{w})=1$ and $G(\bar{w}, z)=1$, the total hiring $h(\bar{w}, z)$ of workers of type $z$ by a firm paying $\bar{w}$ is

$$
h(\bar{w}, z)=\frac{\Omega(z)}{M}\left\{[1-n(z)] \gamma^{0}+n(z) \gamma^{1}\right\}+\int_{t} \gamma^{1} \ell(\bar{w}, t) \Psi(z)\left\{(1-n(z)) \nu^{0}+n(z) \nu^{1}\right\} d t
$$

Note that the employment rate of potential recruits $n(z)$ only controls the contact rate, i.e., the rate at which employed and unemployed workers are contacted about job opportunities. If a peer of a current worker is of type $s$ with probability $\Psi(s)$, she is indirectly recruited to this firm at rate $\left\{[1-n(s)] \nu^{0}+n(s) \nu^{1}\right\}$. This firm's current employees have $\int_{t} \gamma^{1} \ell(\bar{w}, t) d t$ such peers to recruit. In a sense, this indirect recruiting of workers by employees of a firm can be interpreted as a measure of the "capital" the firm has to facilitate recruiting.

The equilibrium measure of workers of type $z$ earning wage $\bar{w}$ is $l(\bar{w}, z)=h(\bar{w}, z) / \delta$ and the total labor force of a firm offering the highest wage $\bar{w}$ in equilibrium is given by

$$
L(\bar{w})=\int_{z} \frac{h(\bar{w}, z)}{\delta} d z
$$

which does not depend on $\bar{w}$, except that it must be the highest offered wage.

In equilibrium, every wage offer to workers of different types must yield the same steady-state profit. In other words, the steady-state profit flow of a firm offering the lowest wage in the market 
$(\underline{w})$ must be equal to the profit of a employer paying the highest wage in equilibrium $(\bar{w})$ :

$$
\pi^{*}=[p-R(1)]\left\{\frac{\frac{\Omega(1)}{M} \gamma^{0}(1-n(1))}{\delta+\gamma^{1}+\left(1-\gamma^{1}\right) \rho^{1}(z)(1-\tilde{G}(R(1)))}\right\}=(p-\bar{w}) L(\bar{w})
$$

Finally, we must also define the minimum of the wage domain. In this aspect, our result very closely resembles that of Burdett and Mortensen (1998) in their version with heterogeneous reservation wages. In particular, let $J(R)$ denote the distribution of reservation wages induced by $R(z)$ and $\Omega(z)$. Then $\underline{w}=\arg \max _{w}(p-w) J(w)$.

\section{Properties of the Equilibrium}

Our first result shows that the earnings distribution of a peer stochastically dominates the earnings distribution in the economy. The proof of this and other results can be found in Appendix 8.

Proposition 1. $\tilde{G}(w)$ first order stochastically dominates $G(w)$.

This result is due to the network structure. Because referred jobs are from workers already on the wage ladder, $G(w)$ will naturally stochastically dominate $F(w)$. Proposition 1 goes further to say that not only are the wages of employed workers better than wages found via direct search, but jobs referred by peers are better than jobs sampled randomly from employed workers. This is because workers of higher type are more likely to be your peer than workers of lower type, and they are also more likely to earn higher wages than workers of lower type. Thus, the wages earned by peers are higher than the wages earned by a typical worker. Thus the "friendship paradox" is an additional source of the benefit of network search over direct search, beyond simply sampling $G(w)$ rather than $F(w)$. In fact, the probability a worker in state $i$ is passed a job above a certain wage rises with $s$. Let

$$
\begin{aligned}
& F_{N}^{0}(w, z)=\gamma^{0}(F(w))+\left(1-\gamma^{0}\right) \rho^{0}(z)(\tilde{G}(w)) \\
& F_{N}^{1}(w, z)=\gamma^{1}(F(w))+\left(1-\gamma^{1}\right) \rho^{1}(z)(\tilde{G}(w))
\end{aligned}
$$

be the probabilities a worker of type $z$ is offered a job that pays less than $w$.

Corollary 1. $F_{N}^{i}(w, z)$ is monotonically increasing in $z$

Note that $F_{N}^{i}(w, z)$ is not actually a probability distribution, and so this does not necessarily imply that the equilibrium offer distribution for workers with large $z$ stochastically dominates that of a worker with lower $z$; such a result depends not only on the probability of being offered a job but also the set of acceptable jobs; the former is increasing, but the latter is decreasing. In our numerical exercises, the former effect dominates by far, but it depends on the structure of $R(z)$, which is defined implicity. 
Our principal result, Proposition 2, states that the earnings distribution of a peer stochastically dominates the offer distribution of firms.

Proposition 2. $\tilde{G}(w)$ first-order stochastically dominates $F(w)$

The wages sampled from peers are better than the wages directly offered by firms. This is the reason network search is better than direct search; it is not necessary that more or better information be passed via networks, or that matches found via network be more productive than those found directly. The network structure of the labor market itself is biased towards higher-wage jobs, which leads to network-found jobs dominating those found directly.

The following lemma states that the job finding rate is increasing in $z$ for workers coming from unemployment and, conditional on a wage level $w$, for job-to-job changes.

Lemma 1. If $\gamma^{0}=\gamma^{1}$ then for $z^{\prime} \geq z$ and a given $w$

$$
\begin{gathered}
\gamma^{0}\left(1-F\left(R\left(z^{\prime}\right)\right)\right)+\left(1-\gamma^{0}\right) \rho^{0}\left(z^{\prime}\right)\left(1-\tilde{G}\left(R\left(z^{\prime}\right)\right)\right) \geq \gamma^{0}(1-F(R(z)))+(1-\gamma) \rho^{0}(z)(1-\tilde{G}(R(z))) \\
\gamma^{1}(1-F(w))+\left(1-\gamma^{1}\right) \rho^{1}\left(z^{\prime}\right)(1-\tilde{G}(w)) \geq \gamma^{1}\left(1-F(w)+\left(1-\gamma^{1}\right) \rho^{1}(z)(1-\tilde{G}(R(z)))\right.
\end{gathered}
$$

As the proof will show, this relies crucially on $\gamma^{1}=\gamma^{0}$, implying that $\frac{\partial R}{\partial z}=0$. However, the numerical results presented in Section 5 demonstrate that for reasonable calibrations where $\frac{\partial R}{\partial z}>0$, job finding rates are still strongly increasing in $z$.

Proposition 3. The distribution of z conditional on finding a job out of unemployment through network search, $\frac{(1-n(z)) \Omega(z) \rho^{0}(z)(1-\tilde{G}(R(z)))}{\int(1-n(z)) \Omega(z) \rho^{0}(z)(1-\tilde{G}(R(z))) d z}$, first-order stochastically dominates the distribution of $z$ conditional on finding a job from unemployment through direct search, $\frac{(1-n(z)) \Omega(z)(1-F(R(z)))}{\int(1-n(z)) \Omega(z)(1-F(R(z))) d z}$, if $\gamma^{0}=\gamma^{1}$.

Workers who find a job through network search are more likely to be well connected in the network. This composition effect is important for the qualitative properties of our model. If a worker is better connected, she receives offers more quickly while unemployed or working. Because workers who find a job through network search are better-connected, it implies that they have shorter unemployment durations and climb the job ladder more quickly.

\section{$5 \quad$ Numerical Results}

We now describe the results from a calibrated version of our model. With this numerical solution, we will explore the quantitative implications of network search for wage and employment dynamics, focusing in particular on how heterogeneity in the number of contacts affects the model's endogenous outcomes, such as job offer arrival rates, the distribution of wage offers by contact 
methods and wage growth paths. In the first step, we describe the features of the model itself, then compare the solution to a similar model without network search, i.e., a Burdett-Mortensen benchmark. Next, we compare the results of a model where workers all have the same job finding rates to one in which there is finding rate heterogeneity. And finally, we use the model to explore and discuss some empirical results about network search and job finding through labor market networks.

To set parameter values, we first choose $b=0, p=1$ and the mass of firms $M=1$, which are all just normalizations. The rest of the parameters must be jointly calibrated. The parameters governing the arrival rate of referrals are particularly important to our study, but not directly identified in standard labor market data. Hence we choose them so that $36 \%$ of openings are filled through a network contact, following findings in Holzer (1988). In terms of our model elements, we calibrate our baseline parameters such that

$$
0.36=\frac{\int_{z} \int_{w} l(w, z) \int_{t=1}^{\infty} \gamma^{1} \times \ell(w, t) \Psi(z)\left\{(1-n(z)) \mathbb{I}_{R(z)<w} \nu^{0}+n(z) G(w, z) \nu^{1}\right\} d t d w d z}{\int_{z} \int_{w} h(w, z) d w d z}
$$

We constrain the arrival rate on and off the job to be the same for network and direct contact offers. Table I presents our baseline calibration parameters.

\begin{tabular}{|c|c|c|}
\hline Parameter & Value & Moment \\
\hline \hline$\gamma^{0}$ & 0.38 & Average acceptance rate out of unemployment, 40\% \\
$\gamma^{1}$ & 0.09 & Average acceptance rate from employment, $2.2 \%$ \\
$\nu^{0}$ & 0.80 & Fraction of hires through the network, 36\% \\
$\nu^{1}$ & 0.19 & Fraction of hires through the network, 36\% \\
$\delta$ & 0.03 & Unemployment rate, $6 \%$ \\
\hline
\end{tabular}

Table I: Baseline calibration parameters

The degree distribution we use in this application is a power-law distribution:

$$
\Omega(z)=(\alpha-1) z^{-\alpha}
$$

where the power-law exponent, $\alpha$, determines how heavy the tail of the distribution is, i.e., how common are nodes with much higher than the mean number of peers. For $\alpha<2$, the mean degree in the network diverges (the tail is "too heavy"), while for $\alpha>3.47$, the network is so sparsely connected that the "giant component" will not exist; in this case, workers will not all be path-connected to each other in the network. We choose $\alpha=2.5$ in our numerical exercise. ${ }^{8}$

Power-law networks have been identified and studied in a variety of contexts, including empirical social networks. For example, the patterns of friendship on Facebook were found to be welldescribed by a power-law in Ugander et al. (2011). The general phenomenon, that the prevalence

\footnotetext{
${ }^{8} \mathrm{~A}$ power law with exponent $\alpha$ is thus equivalent to a Pareto Distribution with shape $\alpha-1$ and scale 1.
} 
in ranked data of the $n$-th ranked object is proportional to $\frac{1}{n^{\alpha}}$, the prevalence of the highest ranked object, for some $\alpha$, has attracted a great deal of interest and study (see, for example, Gabaix (2008) and Newman (2004)). For this reason, we focus on power-laws in our numerical application, though our model can accommodate any arbitrary continuous or discrete degree distribution.

\subsection{Characteristics of the solution}

Before turning to the analysis and discussion of equilibrium objects of our model, such as the offer and employment distributions, it is instructive to consider how some features of labor market networks affect the job search of an individual worker. Broadly, there are two ways in which a worker's network affect her labor outcomes: First, better connected workers find jobs more quickly, and second, they draw from a different offer distribution when they do. Focusing on the first, the probability a worker of type $z$, in state $i$, receives and accepts an offer via a peer in her social network is defined in equation (3). This offer arrival rate $\rho^{i}(z)$ is increasing in $z$, shown in Figure 3. More connections means a better chance of receiving an offer from one of them.

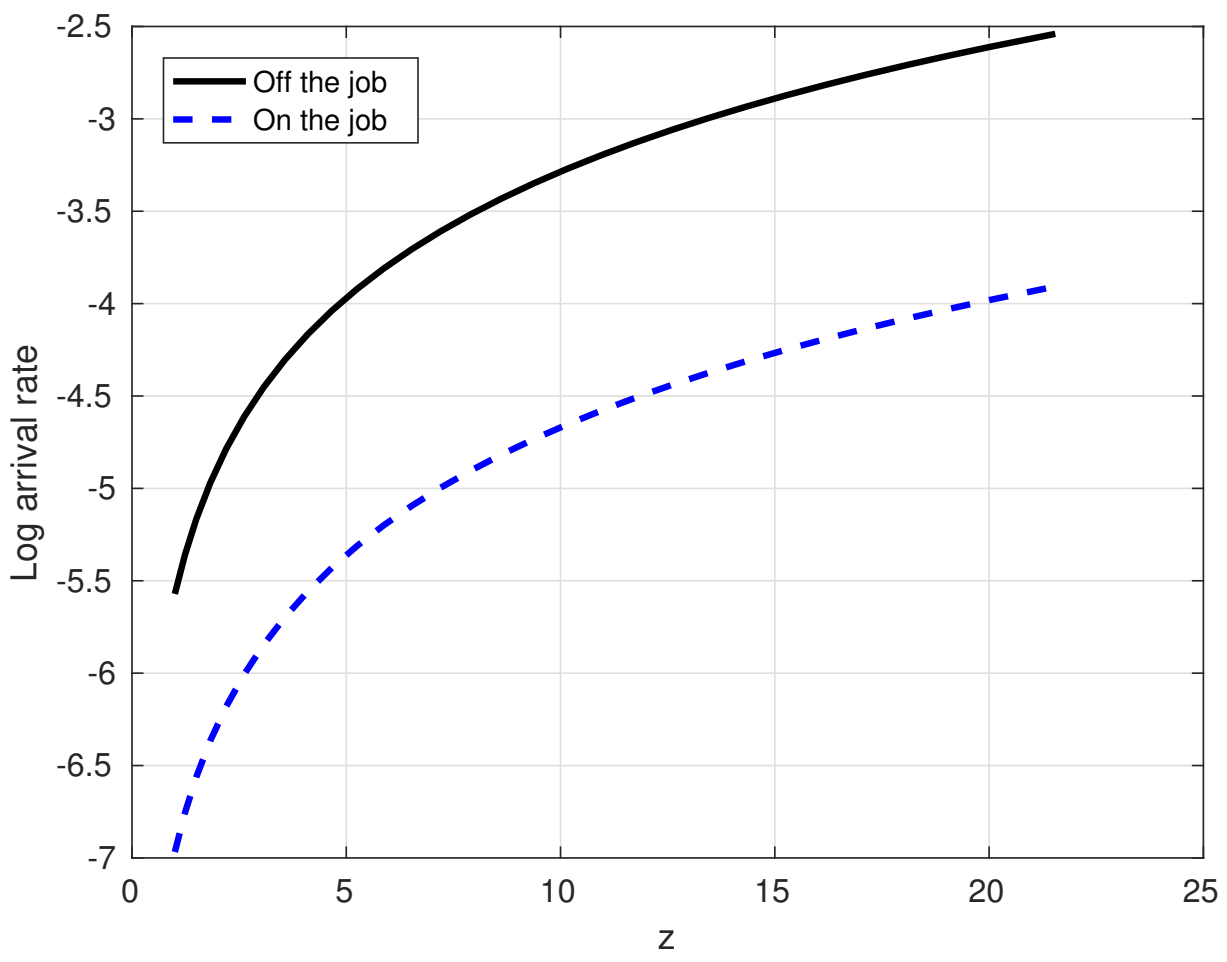

Figure 3: Offer arrival rate through the network

Turning to the second effect of networks, offers through the network are not the same as offers from direct contact with a firm because they have higher wages and hence, those with more connections effectively draw more often from this dominant distribution. Our theoretical result, Proposition 2, showed that the distribution of offers found through a worker's network, $\tilde{G}(w)$, first-order stochastically dominates the distribution, $F(w)$, from which the direct searcher finds 
her job. This is visualized in Figure 4. We plot both offer distributions and it is quite clear how much higher are wages expected to come from a referral than from direct contact, i.e., from $\tilde{G}(w)$ than $F(w)$.

Quantitatively, the difference between expected wages from alternative job search methods comes from two effects. First, network search samples from the current employee's earning distribution rather than the direct offer distribution and the former distribution dominates the latter. This is the logic behind the proof of Proposition 2. Second, referral wages from employees are weighted according to the distribution $\Psi(s)$. Here it is important to recall the paradox of friendship: the probability a worker's peer has $s$ peers herself is not equal to the proportion of workers who have $s$ links, i.e., $\Psi(s) \neq \Omega(s)$. The distribution of peers, $\Psi(s)$, used in weighting $\tilde{G}(s)$ dominates the population distribution of types, $\Omega(z)$.

The average offer draw shown in Figure 4 is an average of two distributions $F(w)$ and $\tilde{G}(w)$. Because workers differ in their number of peers, and therefore the number of draws from $\tilde{G}(w)$, the weights on the two distributions change with $z$. In effect, not only does a better-connected worker draw more offers, she also draws from a better offer distribution. Figure 4 shows the average offer distribution for workers with one and many $(z=20)$ peers. This is the visual counterpart to Corollary 1.

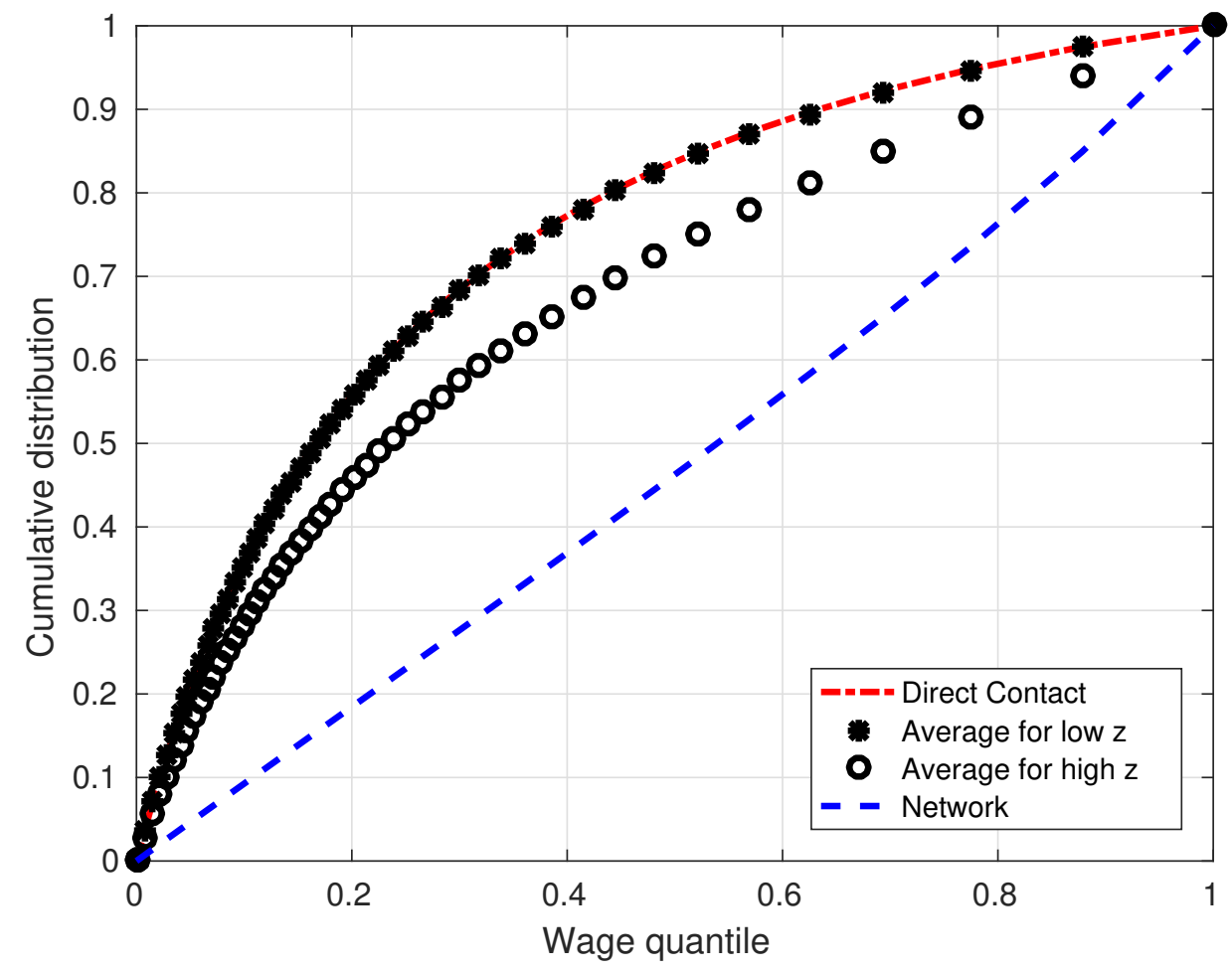

Figure 4: Average distribution of wage offers by contact method conditional on number of peers

Figures 3 and 4 emphasize the two effects of heterogeneity in network connections. Namely, workers with more connections have a higher finding rate and also draw from a dominant distribution. Both effects play into differences in average earnings across the $z$ distribution, shown in 
Figure 5. Conditional on finding a job out of unemployment, the dotted line plots the expected wage as a function of the number of connections. It is upward sloping because the initial wage found through networks, $\tilde{G}(w)$, is higher than through direct contact and better-connected workers get more offers from network search. But, the initial wage is not as strongly affected by network connections as is the average wage among the pool of employed. Driving this increasing difference is the fact that workers with more connections climb the ladder more quickly while they are employed.

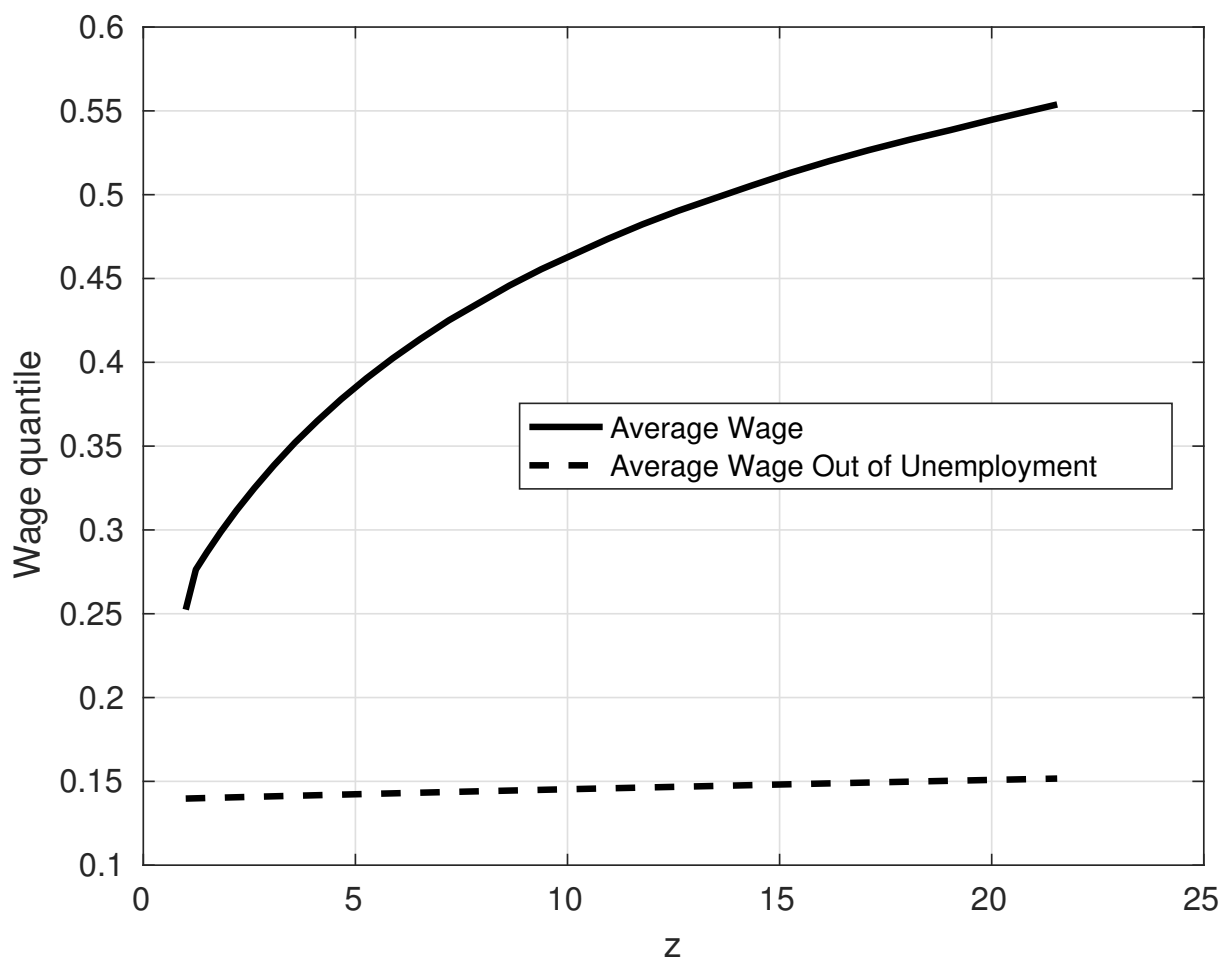

Figure 5: Average wage on initial offer and in steady-state employment

We will try to explicate the mechanism behind the wage differences across $z$ in two ways: First we will show how workers with higher wages are more likely to find their next job through networksearch, then, reversing the logic, better connected workers are more likely to be able to climb high in the ladder. In essence, as workers climb the ladder, the network plays an increasingly important role.

In Figure 6, we show how those who move to a new job are, at higher wages, increasingly likely to do so via their network. In the notation of our model, $\frac{\left(1-\gamma^{1}\right) \rho^{1}(z)(1-\tilde{G}(w))}{\gamma^{1}(1-F(w))+\left(1-\gamma^{1}\right) \rho^{1}(z)(1-\tilde{G}(w))}$ is increasing in $w$ for any given $z$. This is a direct consequence of $\tilde{G}$ first order dominating $F$, so that as we get higher in the distribution, there is more mass left in $1-\tilde{G}(w)$, the probability of a dominating network offer, than in $1-F$. This figure is especially important because we will directly test it in the data in Section 6.2. To better facilitate this comparison to data, we demean the probability. Notice also, the mean is well below the median wage because more transitions occur among low-wage workers. 


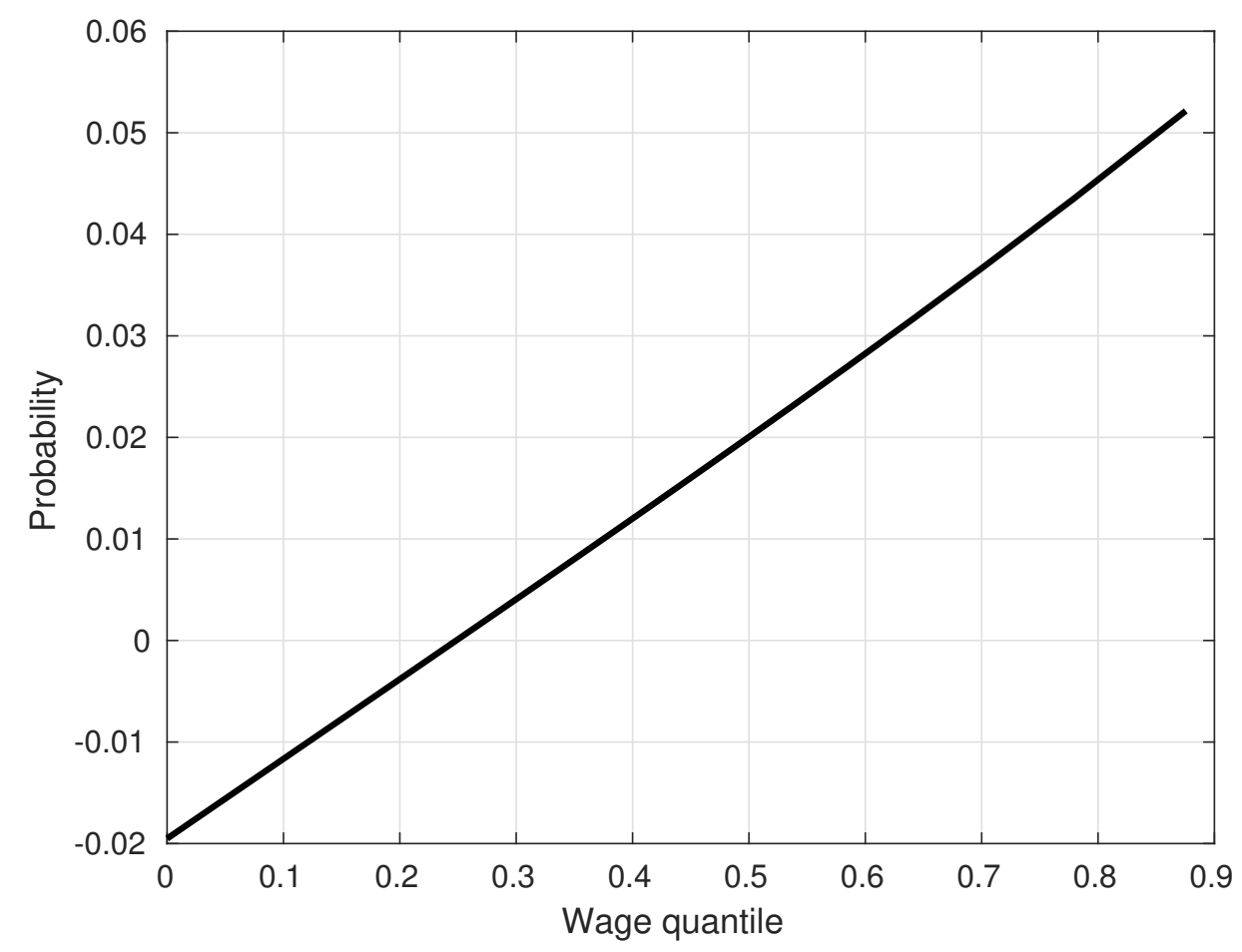

Figure 6: The probability that a worker's next job will be found through network-search.

To demonstrate this idea further, we will consider the half-life before an employed worker's wages are expected to converge on wage $\bar{w}$. As in any model with a job ladder, as a worker's wage increases, she is decreasingly likely to get an offer that dominates and so the speed at which she climbs the ladder is also decreasing. Hence, a good measure of the instantaneous rate a worker is climbing the job ladder is the half-life, which measures half of the expected time to converge to the upper-most wage $\bar{w}$ with wages growing at their instantaneous rate given wage $w$ and connections $z$. To be specific, the half-life is $\frac{\log 2}{\lambda(w, z)}$, where the instantaneous convergence rate, $\lambda(w, z)$, is

$$
\lambda(w, z)=-\log \left(\frac{\bar{w}-E\left[w^{\prime}(w, z)\right]}{\bar{w}-w}\right)
$$

and the "expected wage" is

$$
E\left[w^{\prime}(w, z)\right]=\gamma^{1} \int_{w}^{\bar{w}} x d F(x)+\left(1-\gamma^{1}\right) \rho^{1}(z) \int_{w}^{\bar{w}} x d \tilde{G}(x)+\left(1-\gamma^{1}-\left(1-\gamma^{1}\right) \rho^{1}(z)\right) w .
$$

By starting wage and number of network connections, Figure 7 illustrates how quickly the wage will approach the maximum wage $\bar{w}$. In Figure 7 , we see that the effect of a better network is stronger at high wages. At these high "rungs," the chance of getting a dominating wage offer through the direct offer distribution is quite low compared with the chance of getting one through network search, that is, $1-F(w)$ gets considerably smaller than $1-\tilde{G}(w)$ when $w$ is high. This means that workers with more draws from $\tilde{G}(w)$, i.e., the better-connected workers, have more of 
an advantage. On the other hand, at low rungs, the chance of moving up is relatively invariant to $z$.

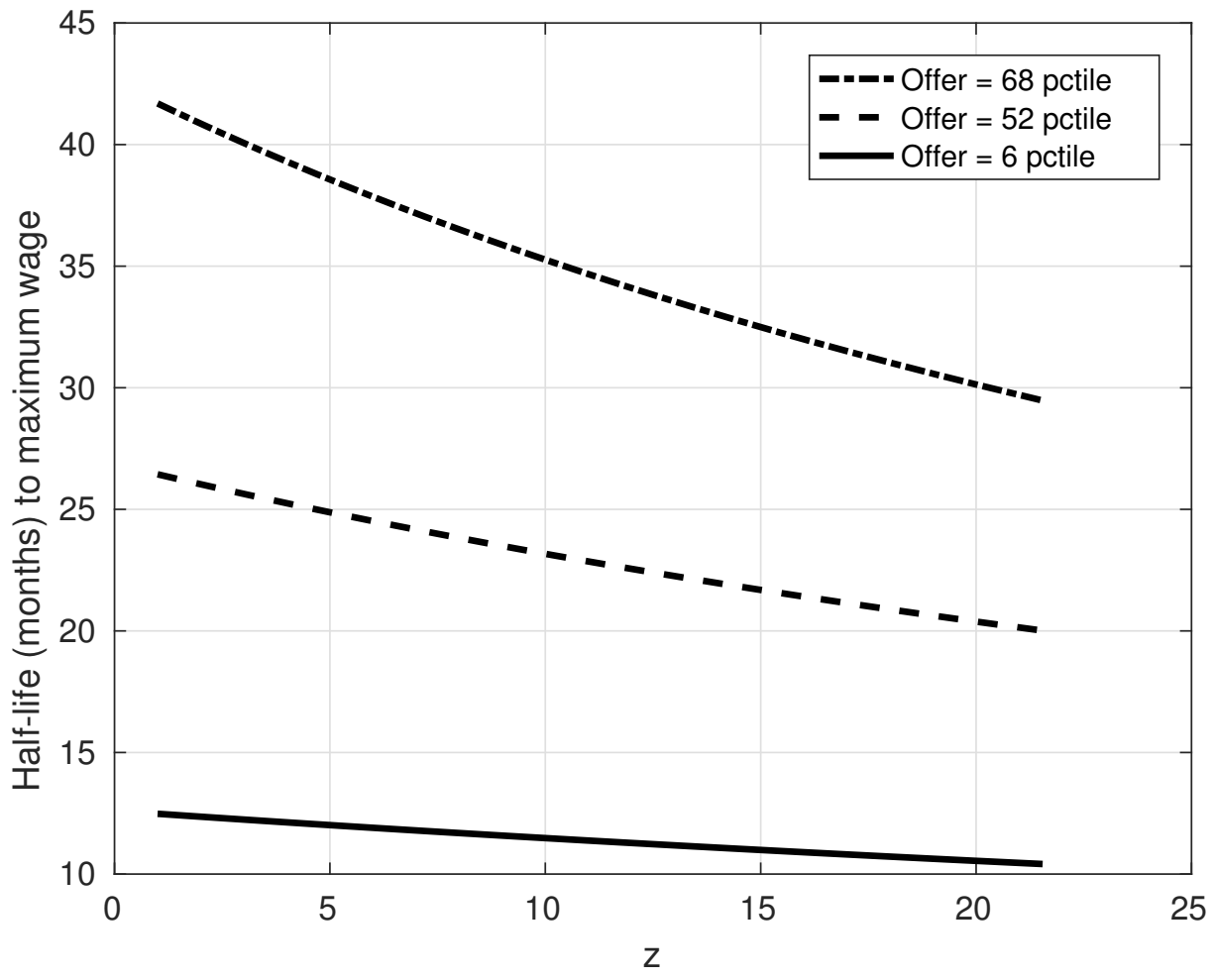

Figure 7: Half-life of wage growth paths to maximum wage: different starting wages, labeled by their quantile in the overall offer distribution, and different network connections $z$.

The effect of network-induced differences in the finding rate and offer distributions is that at higher rungs of the ladder, workers are more likely to find their next job through their network and well-connected workers are better represented at higher rungs.

\subsection{Comparison to Burdett-Mortensen benchmark}

In this section, we compare the quantitative predictions of our model with a benchmark wage posting model, as in Burdett and Mortensen (1998). This paper's crucial modification allows workers to find jobs not only directly from firms but also through their network connections. Here we show quantitatively how differences in the number of network connections - a worker's position in the social network - fundamentally affects on-the-job and off-the-job searches. Then we show the response as the equilibrium distribution of wage postings is changed by this heterogeneity.

The equilibrium of our model with network search is qualitatively different from the equilibrium of the Burdett and Mortensen (1998) model: comparing the equilibrium distribution of offers through direct contact to the offer distribution in a Burdett-Mortensen model with equivalent overall job-finding rate, connected workers engaged in direct search sample from a distribution of offers with higher wages (Figure 8). In other words, the crucial difference between these two offer 
distributions is that with our framework the domain of wage offers is shifted upwards. Hence, a natural conclusion is that whether there is wage dispersion in an economy with on-the-job search depends critically on whether workers find jobs through their network.

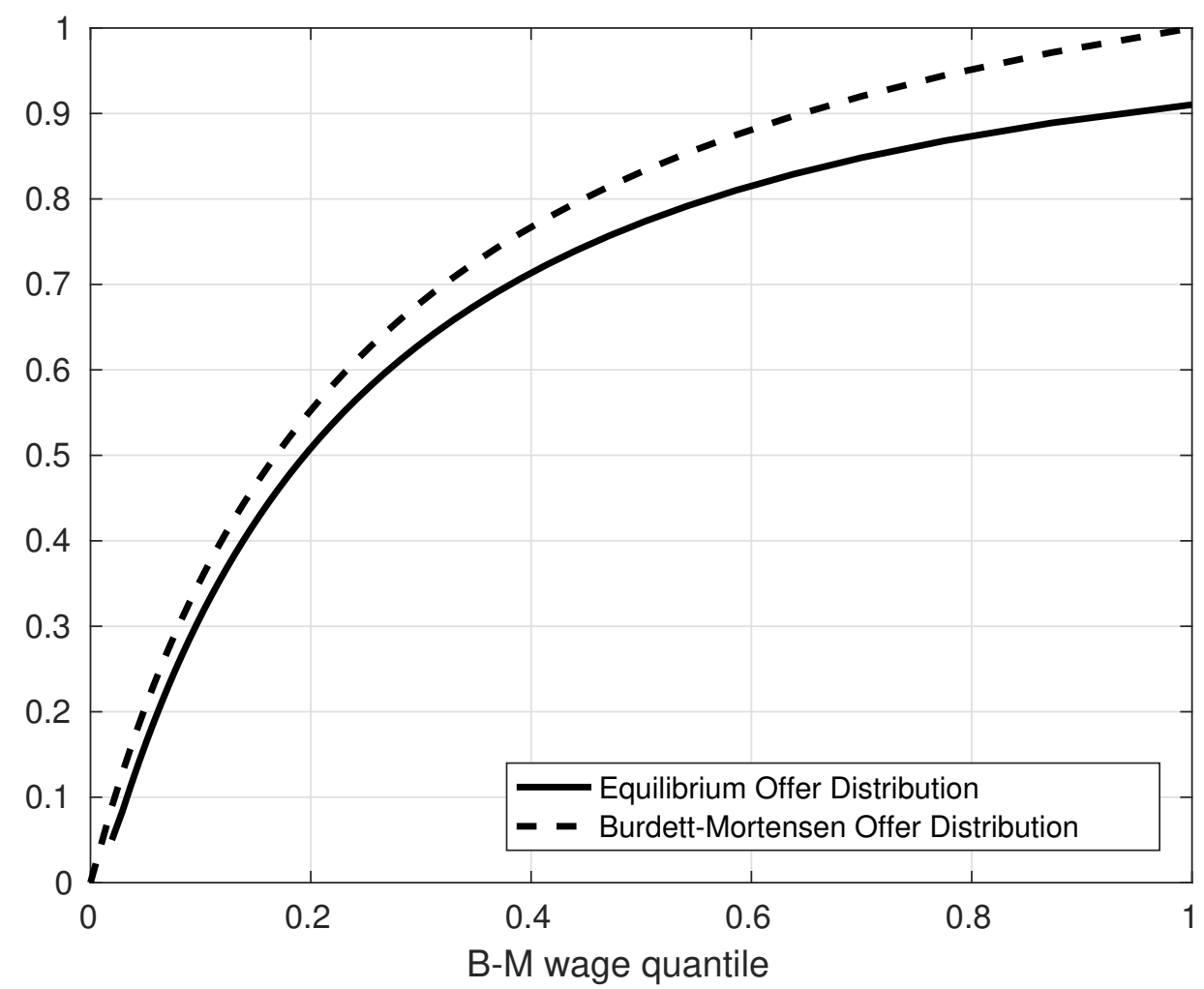

Figure 8: Equilibrium distribution of offers through direct contact against the Burdett-Mortensen offer distribution.

In Figure 9 we contrast the half-life of wage growth paths in our network search model to their respective paths in the Burdett-Mortensen framework. By construction, the arrival rate of jobs is equivalent, but well-networked workers in our setup can climb more quickly because they are drawing better jobs as well. At the very lowest end of $z$, workers actually climb the ladder more slowly in our model. This is because a percentile of the overall offer distribution is actually a higher quantile of their offer distribution and they therefore are less likely to draw a dominating offer and move up. This is not the case in the Burdett-Mortensen model, where the 68th percentile of the offer distribution is the same for everyone and all workers there are equally likely to move.

\subsection{Comparison to heterogeneous finding rates}

Next, we present findings from our model but in which we consider only heterogeneous finding rates, rather than heterogeneity in both the finding rates and offer distributions. We take exactly the distribution of finding rates on and off the job implied by endogenous objects, $\left(\gamma^{i}, \rho^{i}(z)\right)$, the arrival rate of direct and network job offers, respectively, while keeping $\Omega(z)$, the proportion of 


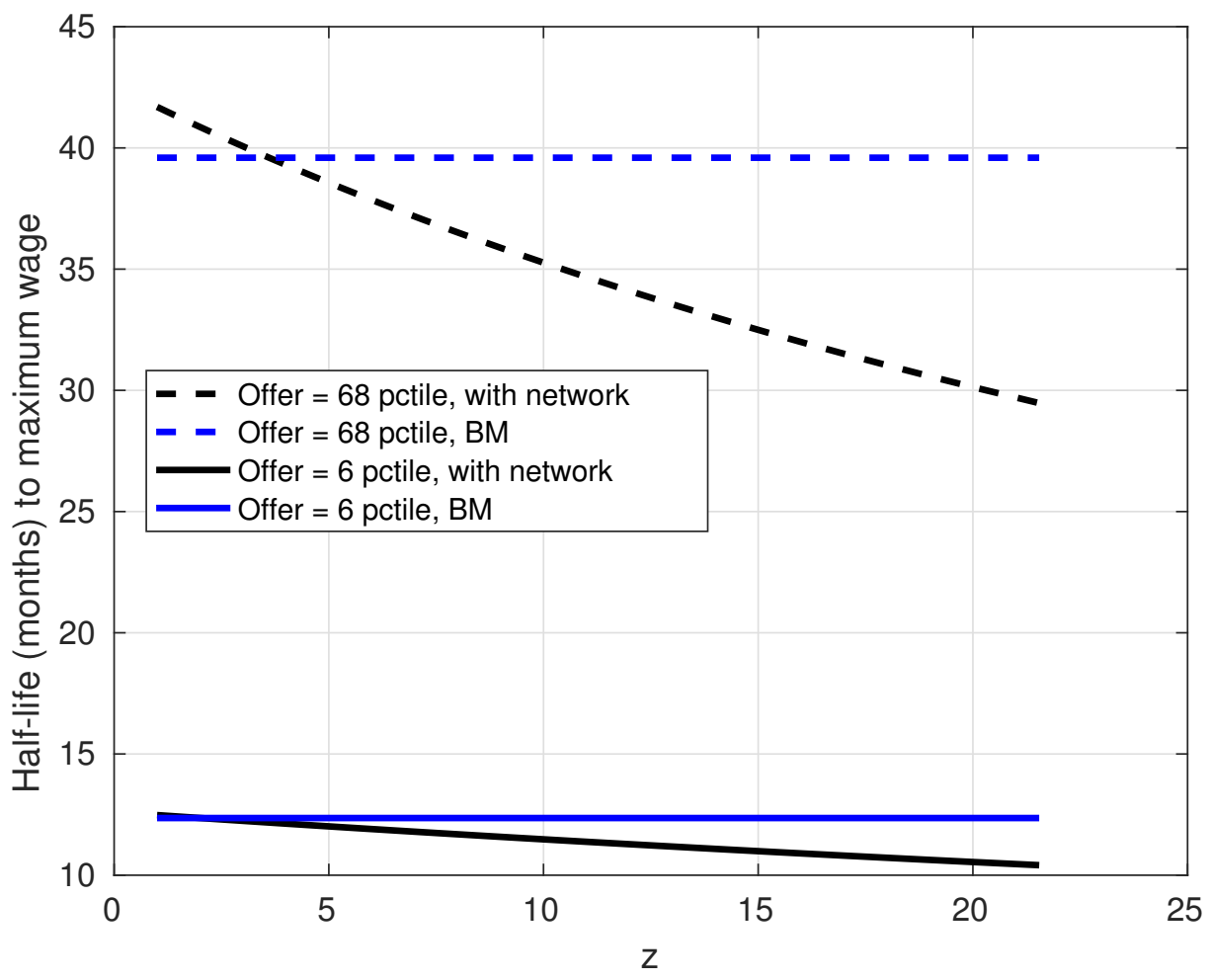

Figure 9: Half-life of wage growth paths to maximum wage: Network Search versus BurdettMortensen benchmark.

workers who have $z$ links, as a fixed object. We integrate over the implied offer distributions to take $F$ and the average sampling from $\tilde{G}$.

The clearest way to see the differences between our model and one with merely heterogeneous finding rates is through Figure 10. The blue lines are the half-lives to the top wage if only finding rates differ and the black line is the half-life in our full network search model. With network search, the half-life decreases more quickly in $z$. Those with higher numbers of peers climb the ladder faster than if they were merely different because of faster offer arrival rates: They also benefit from a distribution of offers that stochastically dominates both the distribution of offers for those with fewer peers, $z$, and also the average offer distribution, the blue line. On the other side, those with few peers would benefit from drawing from the average offer distribution. The point at which the blue and black lines cross is the indifference point, where those with fewer peers draw from a worse distribution in our model than if there were only finding rate heterogeneity. They cross at a relatively small number of peers because of the power-law distribution assumption we made on $\Omega$. There are actually many workers at small levels of $z$ who drew from a worse-than-average distribution. 


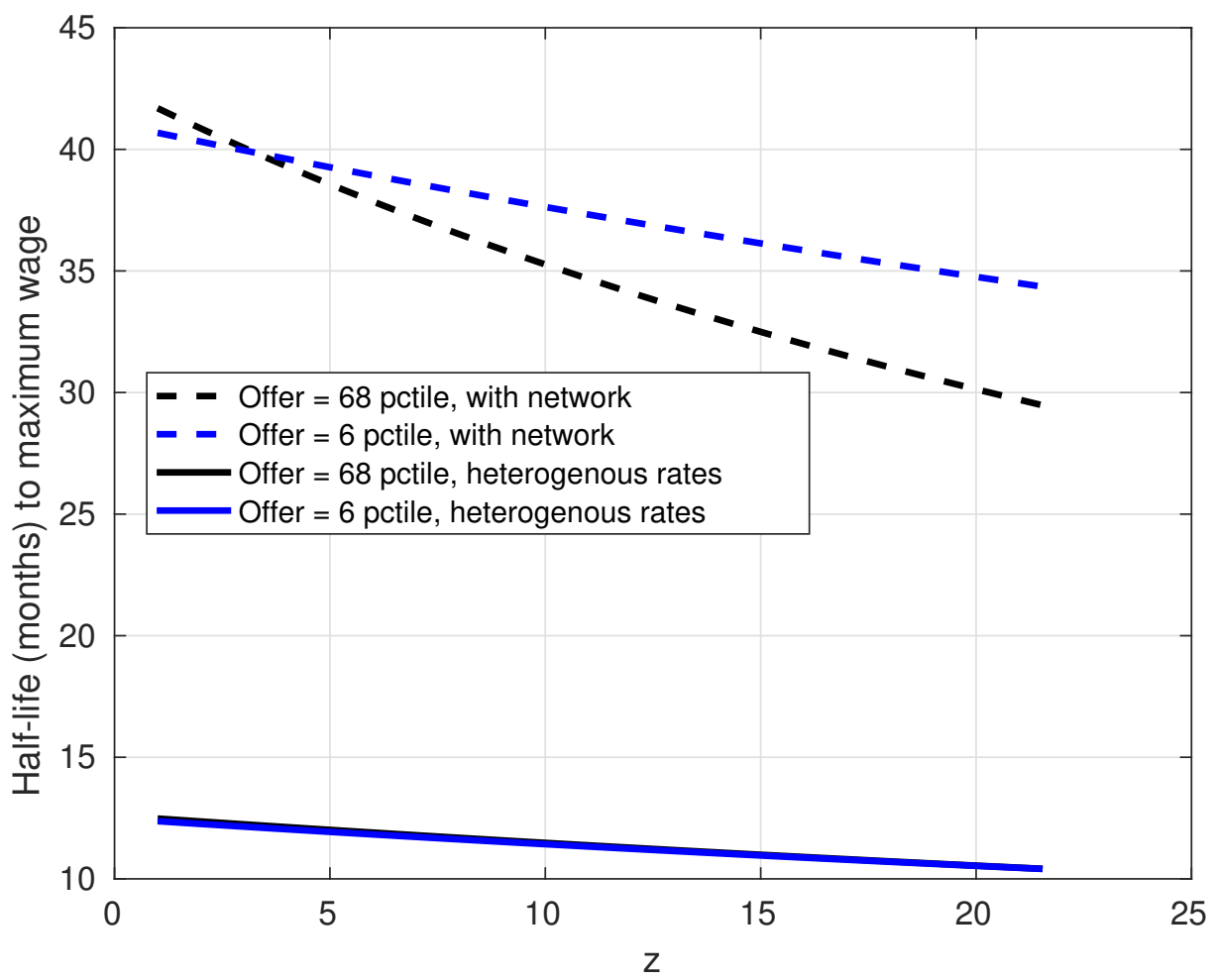

Figure 10: Half-life of wage growth comparing heterogeneous search rates and network search model

\section{$6 \quad$ Understanding some empirical findings}

\subsection{Empirical results through the prism of our model}

There is a great deal of empirical literature pointing to the importance of networks to job-seekers' outcomes. We restrict our attention to three main results in the literature and analyze them through the prism of our model. As we have discussed, a body of empirical studies presents evidence that a worker whose job is found through her network has a higher wage, a longer employment duration and a shorter unemployment spell. These regularities are often attributed to the information that network connections better convey to potential employers (e.g. Simon and Warner (1992), Topa (2011), Cappellari and Tatsiramos (2015), Marmaros and Sacerdote (2002), and Dustmann et al. (2015)), but we show and illustrate numerically that such results may also be due to heterogeneity of network peers and their status in the labor market network.

In fact, our model allows us to understand two channels through which a successful network search has better wages than a successful direct search. First, when a worker finds a job through her own network it implies that she draws from a different (better) wage distribution; as we have shown, $\tilde{G}(w)$ first-order stochastically dominates the distribution $F(w)$ from which the direct searcher finds her job.

But there is another, more subtle ex post reason why wages are higher for an unemployed worker searching through her network. In fact, a worker who found a job through network search 


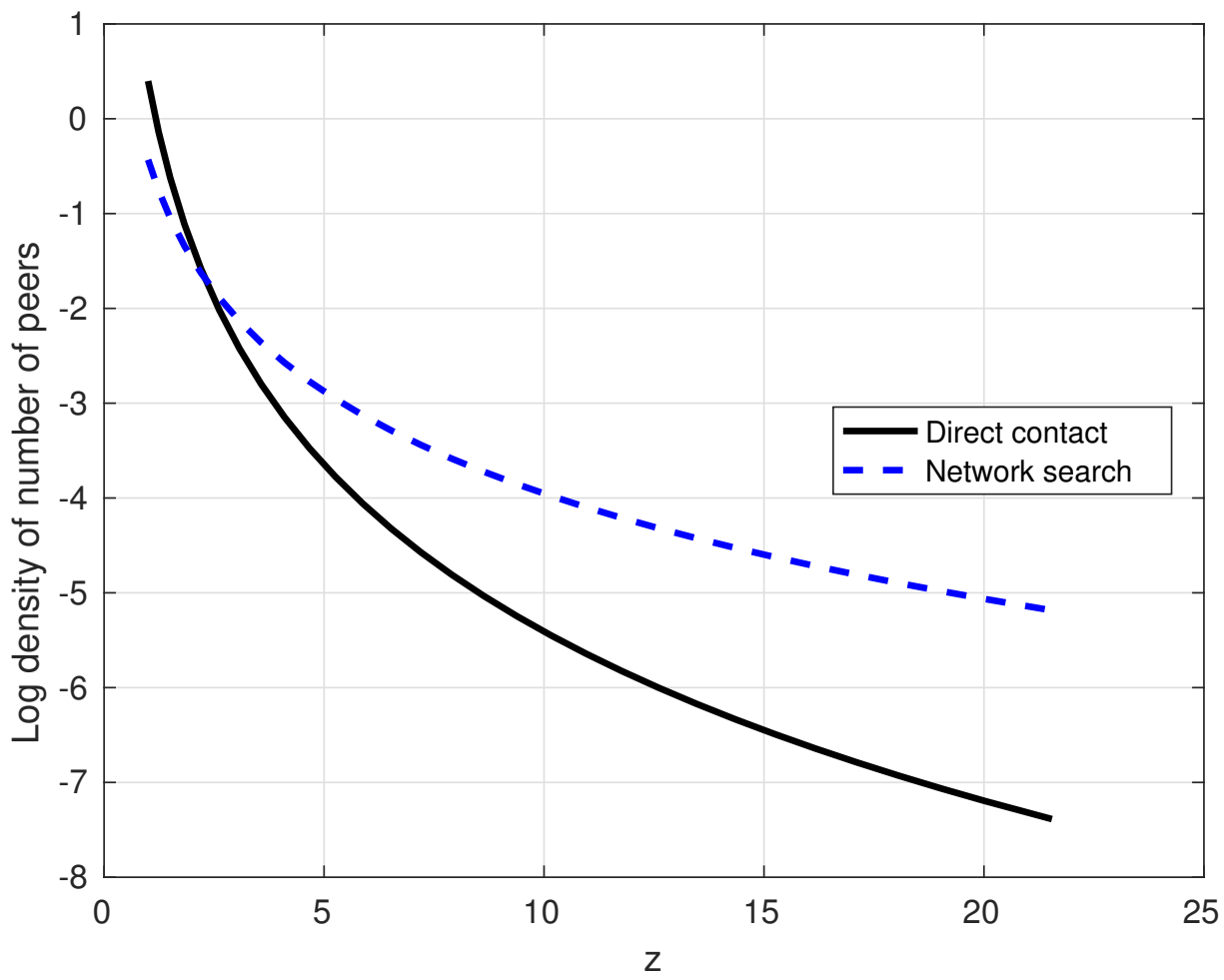

Figure 11: Distribution of number of peers: Direct search and network search.

has brighter prospects because those who had found jobs through networks have, on average, more peers. The intuition is that one with more network connections gets proportionally more of her draws from the network distribution than a worker with fewer links. That is, $\frac{\rho^{0}(z)}{\gamma^{0}}$ is increasing in $z$ simply because the probability $\rho^{0}(z)$ that an unemployed worker of type $z$ receives and accepts an offer via a peer in her social network is increasing in $z$. Then, among the pool of searchers who found a job through peers, more are better-connected. To put this another way, the expected number of connections of a worker, conditional on getting a job through network search, is greater than the expected number of connections if a worker finds a job through direct search:

$$
\frac{\int z(1-n(z)) \Omega(z)\left(1-\gamma^{0}\right) \rho^{0}(z)(1-\tilde{G}(R(z))) d z}{\int(1-n(z)) \Omega(z)\left(1-\gamma^{0}\right) \rho^{0}(z)(1-\tilde{G}(R(z))) d z}>\frac{\int z(1-n(z)) \Omega(z) \gamma^{0}(1-F(R(z))) d z}{\int(1-n(z)) \Omega(z) \gamma^{0}(1-F(R(z))) d z}
$$

In Figure 11 we demonstrate this idea in our calibrated model, plotting the distribution of the number of peers conditional on whether a worker finds a job through network or direct search. The compositional differences between workers finding jobs directly or through a network will drive the differences between these groups in their endogenous variables.

Table II illustrates the expected differences between workers finding jobs out of unemployment through network or directed search. Workers who find jobs via their network of contacts have on average more peers, spend less time searching and should expect a higher initial wage than 
those workers who become employed through direct search. As a consequence of having a higher matched wage, jobs found through the network are expected to last longer. Essentially, there are two forces at work: conditional on the same wage, a worker who finds a job through her network probably has more peers and therefore finds new jobs more quickly and has a shorter tenure at the first job. However, because the initial wage of a job found through the network is higher, and these jobs last longer, this effect dominates. Hellerstein et al. (2015) and Cingano and Rosolia (2012) present empirical evidence of lower rates of job turnover and rapid re-employment of more-networked workers.

\begin{tabular}{|l|c|c|}
\hline & Network Search & Direct Search \\
\hline \hline Percentile of Expected Initial Wage & 31.72 & 13.91 \\
Expected Duration of Job Match & 6.89 years & 3.18 years \\
Average $z$ Relative To Unemployment Pool & 1.81 & 1.00 \\
Search Time Relative to Average & 0.983 & 1.002 \\
\hline
\end{tabular}

Table II: Expected differences between workers finding jobs through network or directed search.

Figure 12 shows the expected duration of a job match conditional on wage for direct search and network search. This is different from what we have in Table II, where numbers for expected duration of job match are not conditional on wage. Conditional on wage, the worker finding a job through her network has only $98 \%$ the expected duration of an average job because these workers are better-connected and therefore have higher offer arrival rates. Overall, however, these matches last more than twice as long because they are at higher wages and hence have a lower probability of a dominating offer.

\subsection{Further evidence from the Survey of Consumer Expectations}

In this subsection we present further empirical evidence for our mechanism using the Survey of Consumer Expectations (SCE). This survey, commissioned by the Federal Reserve Bank of New York, asks households a battery of questions about their expectations regarding their own future and the macroeconomy. There is also a once a year labor supplement with detailed questions about job search and, particularly useful for our purposes, the methods of search they are using and have used.

A limitation of the SCE is that its sample size is quite small, especially because there is only one cross-section of data that is publicly available. For this reason, we focus on the reported search method of currently employed workers: Employees are asked how they found their current job. ${ }^{9}$ We categorize each worker by whether they found their job through a job referral or not. The SCE also allows us to distinguish the source of referral so that we can define referrals as those coming

\footnotetext{
${ }^{9}$ Presumably, we could also use data on methods of those currently searching, but this gives us far fewer observations than looking at all of those currently working.
} 


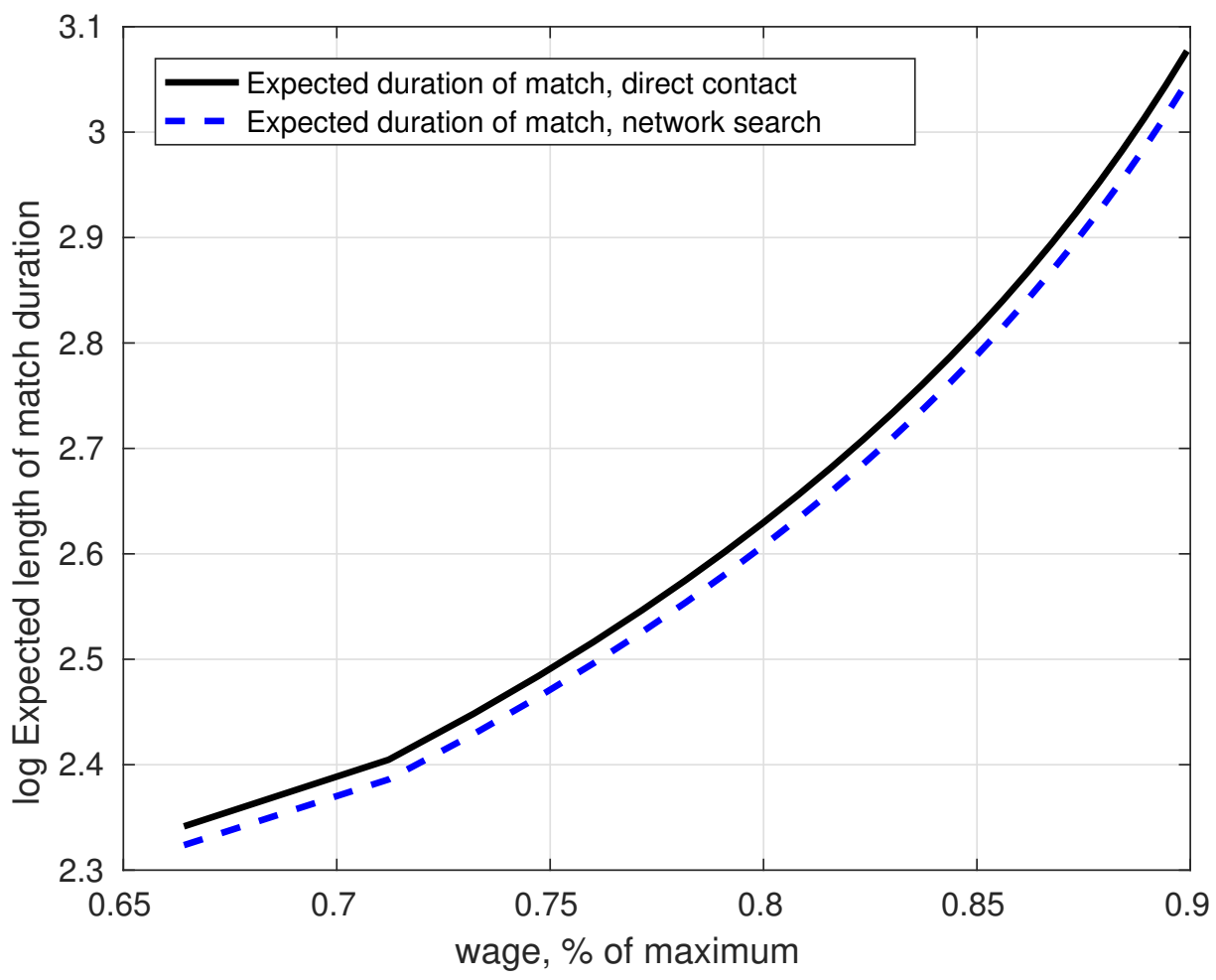

Figure 12: Expected duration of a job match conditional on wage: Direct search and network search.

through weak-ties connections, as suggested by our model and prior work. ${ }^{10}$ In the sample $24 \%$ of jobs were found through networks and the rest through a variety of methods. Beyond details of the search process, we also have data on the earnings and characteristics of this job, earnings in the job they left and what caused their separation.

To select our sample, we require that workers report the search method that led to their current job, as well as the salary associated with it and employment characteristics we use as regressors. We allow either full or part-time employment but restrict the sample to those making at least $\$ 80$ per week. We drop those who did not transition from prior employment or unemployment. Because workers may report their current and past salary as either annual, weekly or hourly, we convert all to weekly salaries. To inflate hourly wages, we multiply by reported usual hours and divide annual salaries by 52 weeks. ${ }^{11}$ Unfortunately, the public version of the SCE does not include data on worker's demographic characteristics, otherwise we could restrict ourselves to a homogeneous sample or statistically control these differences.

We will first confirm that, consistent with evidence in Dustmann et al. (2015), jobs found through referral have higher salaries. As discussed in Section 4, this is an aspect central to the mechanism in our model, in which network-search gives workers access to job offers from

\footnotetext{
${ }^{10}$ Specifically, the SCE categorizes referrals as those from business associates or from "a friend or relative." We take the former as a referral.

${ }^{11}$ Workers do not directly report their usual hours in their prior employment, instead they list the change from their current job, which could, of course, introduce some measurement error.
} 
a distribution that first-order stochastically dominates the random-search offer distribution. To find empirical evidence, we estimate a logit, predicting whether the current job was reportedly found through a network referral or direct search. Formulating the estimation as such allows us to control for firm-effects that we know also affect wages and the probability of hiring through referral. Specifically, we estimate for worker $i$ with employer $j$

$$
\operatorname{Pr}[\text { Network find }]=f\left(\beta_{1} \text { salary }_{i j}+\beta_{2} \text { small }_{j}+\beta_{3} J 2 J_{i j}+\beta_{4} P T_{i j}\right) .
$$

Table III presents the estimation results. In each specification we control for firm industry and size. ${ }^{12}$. In the first column, we show the relationship between a worker's earnings and the probability that they found their job through a network referral. Those who earn more tend to have found their job through their network. In Column (2) we substitute the size dummies for a single dummy representing those with fewer than 500 employees to illustrate that smaller firms tend to hire through referrals, confirming past findings. In Columns (3) and (4) we show that the salary estimates are robust to controlling for whether the transition was directly job-to-job and whether it is part or full time. We categorize a "voluntary job-to-job" transition if there was no interstitial unemployment spell and the original job did not end and follow the SCE in defining part-time and full-time. The estimates of these ancillary coefficients are rather imprecise but the signs are as expected.

\begin{tabular}{lcccc}
\hline & $(1)$ & $(2)$ & $(3)$ & $(4)$ \\
\hline Log weekly salary & $0.0754^{* *}$ & $0.0805^{* *}$ & $0.0748^{* *}$ & $0.0723^{* *}$ \\
& $(3.15)$ & $(3.41)$ & $(3.01)$ & $(2.76)$ \\
$<500$ employees & & $0.0920^{\dagger}$ & & \\
& & $(1.86)$ & & \\
Voluntary Job-to-Job & & & & \\
& & & $(0.0064$ & 0.0021 \\
& & & & $(0.05)$ \\
Part-time & & & & -0.0444 \\
& & & & $(-0.69)$ \\
\hline Firm Size Dummies & $\mathrm{X}$ & $\mathrm{X}$ & $\mathrm{X}$ & $\mathrm{X}$ \\
Industry Dummies & $\mathrm{X}$ & $\mathrm{X}$ & 577 \\
\hline Observations & 577 & 577 & & 577 \\
Pseudo $R^{2}$ & & & & \\
\hline
\end{tabular}

Table III: Estimated marginal effects from Equation 29

We can go further with the SCE towards verifying distinguishing predictions from our model. In particular, we predict that workers higher in the job ladder will tend more often to find jobs

\footnotetext{
${ }^{12}$ We use the size bundles available in the SCE and collapse these 2-digit industry codes into 1-digit bins combining industries 1-5, 6-8, 10-14, 16-19 and another with 15 and 9.
} 
through network search. Thus, we should find that workers with higher prior earnings will also be more likely to have found their job through their network. Figure 13 provides casual evidence: Among the job-to-job switchers, we plot the residual probability that a job was found via network search against the earnings from which the worker left. To compute the residual probability, we estimate a logit on firm industry and size. We show the 5 th through 95 th percentile of the earnings distribution, as observations become more spread out at the tails. Then it is clear that workers with low earnings are less likely to find their next job through a network. At the bottom of the earnings distribution, workers are $10 \mathrm{pp}$ less likely than average to find their next job via their network, whereas at the top of the earnings distribution, they are almost 5 pp more likely.

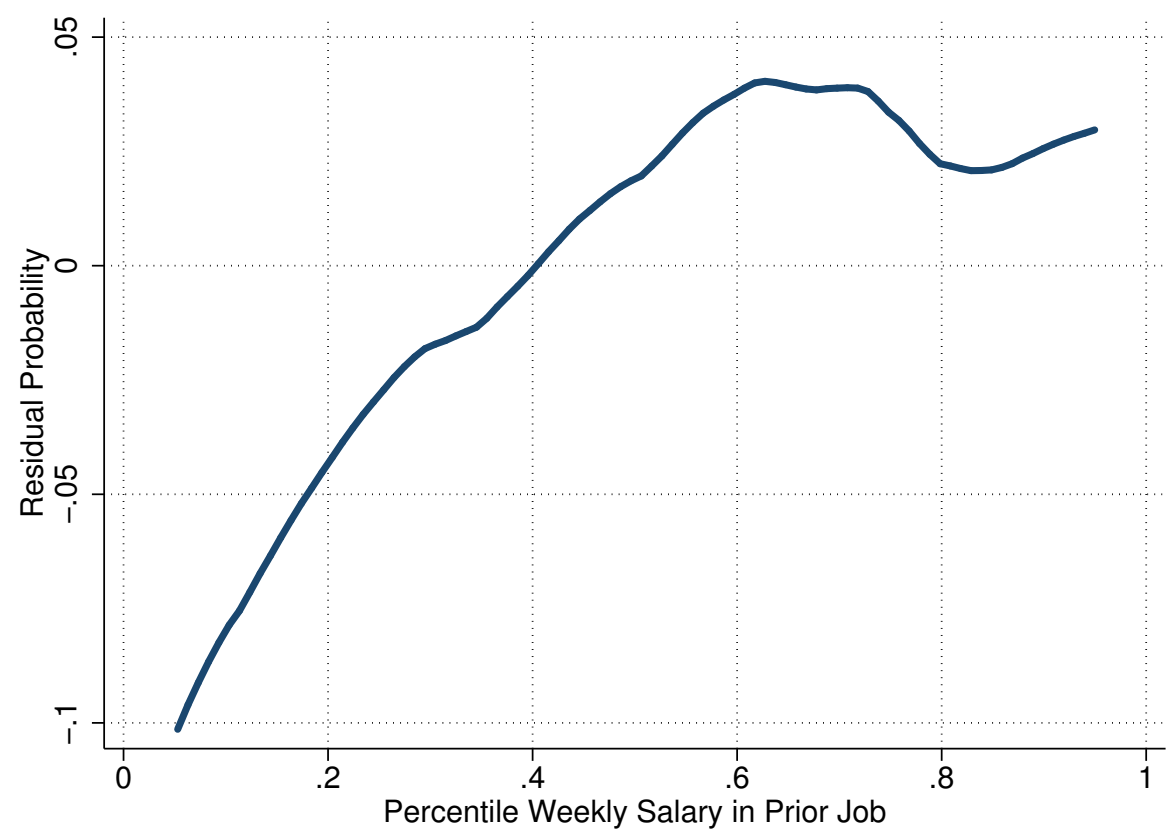

Figure 13: The conditional probability of finding a job through network search by prior salary.

Finally, in Table IV we estimate Equation 29 but replace current salary with salary at one's prior employer, the pay rate just before leaving. The sample is now reduced because we are only considering job-to-job changers and not everyone who reports their previous salary. Still, the effects are quite strong. If a worker changes jobs his likelihood of utilizing a network would increase by about $6.5 \mathrm{pp}$ if her salary were one standard deviation above the mean, 0.79 log points higher. This result is strongly statistically significant and provides strong support for our model. We showed this in Figure 6. Recall, there are two reasons for this. At higher wages workers are more likely to be well connected and hence sample more frequently from the network distribution. Also, because the network-search offer distribution first-order stochastically dominates the direct-search offer distribution, there is an increasing share of acceptable poaching offers at higher wages. In the notation of our model $\frac{1-\tilde{G}\left(w_{1}\right)}{1-F\left(w_{1}\right)} \geq \frac{1-\tilde{G}\left(w_{2}\right)}{1-F\left(w_{2}\right)}$ for $w_{1} \geq w_{2}$, as we discussed to explain Figure 6 . 


\begin{tabular}{|c|c|c|c|}
\hline & $(1)$ & $(2)$ & (3) \\
\hline Log prior employer weekly salary & $\begin{array}{c}0.0861^{* *} \\
(2.70)\end{array}$ & $\begin{array}{c}0.0832^{* *} \\
(2.72)\end{array}$ & $\begin{array}{c}0.0796^{*} \\
(2.50)\end{array}$ \\
\hline$<500$ employees & & $0.1387^{\dagger}$ & \\
\hline
\end{tabular}

Voluntary Job-to-Job

Part-time $\quad-0.2383$

\begin{tabular}{lccc} 
& & & $(-1.21)$ \\
\hline Firm Size Dummies & $\mathrm{X}$ & & $\mathrm{X}$ \\
Industry Dummies & $\mathrm{X}$ & $\mathrm{X}$ & $\mathrm{X}$ \\
\hline Observations & 260 & 260 & 260 \\
Pseudo $R^{2}$ & & & \\
\hline$t$ statistics in parentheses & & & \\
${ }^{\dagger} p<0.10,{ }^{*} p<0.05,{ }^{* *} p<0.01$ & & &
\end{tabular}

Table IV: Estimated marginal effects, replacing prior earnings in Equation 29

\section{Conclusion}

In this paper, we have explored how network search affects wage and employment dynamics. We embedded the well documented evidence that jobs are found through networks into an equilibrium wage posting model with on-the-job search. In our model workers hear about job opportunities through their social networks (peers, acquaintances and friends) and formal search (employment agencies and direct applications to the employers). Heterogeneity in the worker's position within the network leads to heterogeneity in wage and employment dynamics: better-connected workers climb the job ladder faster and do not fall as far. These workers also pass along higher quality referrals, which benefits their connections. In our environment, wage offer distributions are natural consequences of frictions in the job information propagation mechanism through different channels. Differences in job finding rates and reservation wages are a function of a worker's position in the social network because the number of connections governs how quickly a worker can expect to find a referral from a peer. This feature alone provides a micro-foundation for finding-rate heterogeneity; but further, we show that network-based search is important for the type of jobs that are found.

We show that the wage offer distribution via social networks first-order stochastically dominates the wage offer distribution via direct search. Job offers learned from a worker's peers are endogenously better than those a worker would likely find through direct search. In our calibration exercise, we show how workers differ based on whether they found their job through network or direct search. Those who find jobs through network-search generally have more peers than a worker who found her job via direct search. This different composition then manifests itself in different labor market transitions. Because those who found a job through network search have 
more peers, they find jobs from unemployment more quickly. Once employed, a worker who found her job through her network, and is therefore better-connected, experiences higher wage growth for the rest of her career than another who found an equivalent job through direct search.

Finally, we present new evidence in support of our framework from the SCE. Central to our model, to arrive at a high rungs on the job-ladder a worker is more likely to use network-search. We present direct evidence of this. We show that workers with a higher wage are significantly more likely to find their next job via a referral through their network.

Our analysis has abstracted from many quantitatively important factors, particularly firm-side heterogeneity and other types of worker-side heterogeneity. It is, however, a very flexible starting point to which these other features can be grafted. Our approach, simplifying the state using the mean field approach, makes many rich models with network search tractable. We hope that, in the future, it can be used to study how network heterogeneity affects classic questions regarding worker-side heterogeneity such as earnings inequality and unemployment duration dependence. Furthermore, network search can be uniquely useful in understanding measured vacancy yields across sectors and time.

\section{Appendix}

\subsection{Proof of Proposition 1}

We have that

$$
\Psi(z)=\frac{z \Omega(z)}{\langle z\rangle}
$$

Therefore

$$
\frac{\Omega(z)}{\Psi(z)}=\frac{\langle z\rangle}{z}
$$

The likelihood ratio $\frac{\Omega(z)}{\Psi(z)}$ is monotonically declining; $\Psi$ and $\Omega$ therefore satisfy the monotone likelihood ratio property, and this implies that $\Psi$ first order stochastically dominates $\Omega$. Therefore,

$$
\int u(z) \Psi(z) d z \leq \int u(z) \Omega(z) d z
$$

for any smooth monotonic function $u(z)$. Applied to the earnings distribution $G(w, z)$, this implies

$$
\begin{aligned}
\int G(w, z) \Psi(z) d z & \leq \int G(w, z) \Omega(z) d z \\
\tilde{G}(w) & \leq G(w)
\end{aligned}
$$

as was to be shown. 


\subsection{Proof of Corollary 1}

Recall that

$$
F_{N}^{i}(w, z)=\gamma^{i}(F(w))+\left(1-\gamma^{i}\right) \rho^{i}(z)(\tilde{G}(w))
$$

which depends on $z$ only through $\rho^{i}(z)$, defined as in Equation 3

$$
\rho^{i}(z)=\left(1-\left[1-\int_{s} \Psi(s) n(s) \gamma^{1} \frac{\nu^{i}}{s} d s\right]^{z}\right)
$$

Since $\left[1-\int_{s} \Psi(s) n(s) \gamma^{1} \frac{\nu^{i}}{s} d s\right]<1, \rho^{i}(z)$ is increasing in $z$ :

$$
\frac{\partial \rho^{i}(z)}{\partial z}=-\left[1-\int_{s} \Psi(s) n(s) \gamma^{1} \frac{\nu^{i}}{s} d s\right]^{z} \log \left(1-\int_{s} \Psi(s) n(s) \gamma^{1} \frac{\nu^{i}}{s} d s\right)
$$

Therefore, $F_{N}^{i}(w, z)$ is increasing in $z$.

\subsection{Proof of Proposition 2}

Recall that

$$
\begin{aligned}
& F_{N}^{0}(w, z)=\gamma^{0}(F(w))+\left(1-\gamma^{0}\right) \rho^{0}(z)(\tilde{G}(w)) \\
& F_{N}^{1}(w, z)=\gamma^{1}(F(w))+\left(1-\gamma^{1}\right) \rho^{1}(z)(\tilde{G}(w))
\end{aligned}
$$

are the off-the-job and on-the-job offer probabilities, including both direct and network search, respectively. We can write

$$
\begin{aligned}
G(w, z) & =\frac{1-n(z)}{n(z)} \frac{F_{N}^{0}(w, z)-F_{N}^{0}(R(z), z)}{\delta+\left(F_{N}^{1}(\bar{w}, z)-F_{N}^{1}(w, z)\right)} \\
\frac{1-n(z)}{n(z)} & =\frac{\delta}{F_{N}^{0}(\bar{w}, z)-F_{N}^{0}(R(z), z)}
\end{aligned}
$$

Substituting, we have

$$
\begin{aligned}
G(w, z) & =\frac{\delta \frac{F_{N}^{0}(w, z)-F_{N}^{0}(R(z), z)}{F_{N}^{0}(\bar{w}, z)-F_{N}^{0}(R(z), z)}}{\delta+\left(F_{N}^{1}(\bar{w}, z)-F_{N}^{1}(w, z)\right)} \\
& =\frac{\frac{F_{N}^{0}(w, z)-F_{N}^{0}(R(z), z)}{F_{N}^{0}(\bar{w}, z)-F_{N}^{0}(R(z), z)}}{1+\frac{1}{\delta}\left(F_{N}^{1}(\bar{w}, z)-F_{N}^{1}(w, z)\right)} \\
& \leq \frac{F_{N}^{0}(w, z)-F_{N}^{0}(R(z), z)}{F_{N}^{0}(\bar{w}, z)-F_{N}^{0}(R(z), z)} \\
& \leq F_{N}^{0}(w, z)-F_{N}^{0}(R(z), z) \quad \leq F_{N}^{0}(w, z)
\end{aligned}
$$


where the penultimate inequality follows because $F_{N}^{0}(\bar{w}, z)>F_{N}^{0}(w, z)>F_{N}^{0}(R(z), z)$, and ultimate inequality follows because $F_{N}^{0}(R(z), z) \geq 0$. Thus, we have

$$
G(w, z) \leq F_{N}^{0}(w, z)
$$

showing the the earnings distribution of workers of type $z$ first order stochastically dominates the "weighted" offer distribution for these workers. This implies

$$
\begin{aligned}
& G(w, z) \leq F_{N}^{0}(w, z) \\
& G(w, z) \leq \gamma^{0}(F(w))+\left(1-\gamma^{0}\right) \rho^{0}(z)(\tilde{G}(w))
\end{aligned}
$$

Integrating both sides with respect to the neighbor type distribution $\Psi(z)$, we have

$$
\tilde{G}(w) \leq \gamma^{0}(F(w))+\left(1-\gamma^{0}\right) \tilde{G}(w) \tilde{\rho}^{0}
$$

where

$$
\tilde{\rho}^{0}=\int \rho^{0}(z) \Psi(z) d z
$$

This implies

$$
\tilde{G}(w) \leq \frac{\gamma^{0} F(w)}{1-\left(1-\gamma^{0}\right) \tilde{\rho}^{0}} \leq F(w)
$$

where the final inequality follows because $\frac{\gamma^{0}}{1-\left(1-\gamma^{0}\right) \tilde{\rho}^{0}} \leq 1$. Thus the result is proven.

\subsection{Proof of Lemma 1}

We will show that

$$
\begin{aligned}
& \gamma^{0}+\left(1-\gamma^{0}\right) \rho^{0}\left(z^{\prime}\right) \geq \gamma^{0}+\left(1-\gamma^{0}\right) \rho^{0}(z) \\
& \gamma^{1}+\left(1-\gamma^{1}\right) \rho^{1}\left(z^{\prime}\right) \geq \gamma^{1}+\left(1-\gamma^{1}\right) \rho^{1}(z)
\end{aligned}
$$

Using the definition of $R(z)$, Equation 8,reprinted here for convenience:

$R(z)=b+\left(\gamma^{0}-\gamma^{1}\right)\left\{\int_{R(z)}^{\bar{w}} V_{x}^{1}(z, x)[1-F(x)] d x\right\}+\left[\left(1-\gamma^{0}\right) \rho^{0}(z)-\left(1-\gamma^{1}\right) \rho^{1}(z)\right]\left\{\int_{R(z)}^{\bar{w}} V_{x}^{1}(z, x)(1-\tilde{G}(x)\right.$

we can see that if $\gamma^{0}=\gamma^{0}$ then $R(z)=b \forall z$ and then trivially $\frac{\partial R(z)}{\partial z}=0$. Therefore for any $z, z^{\prime}$, $\left(1-F(R(z))=\left(1-F\left(R\left(z^{\prime}\right)\right)\right.\right.$ and $\left(1-\tilde{G}(R(z))=\left(1-\tilde{G}\left(R\left(z^{\prime}\right)\right)\right.\right.$. This means the only differences are $\rho^{0}\left(z^{\prime}\right) \geq \rho^{0}(z)$ and $\rho^{1}\left(z^{\prime}\right) \geq \rho^{1}(z)$. This follows directly from the definition of $\rho^{i}(z)$ in Equation 
3:

$$
\frac{\partial \rho^{i}(z)}{\partial z}=-\left[1-\int_{s} \Psi(s) n(s) \gamma^{1} \frac{\nu^{i}}{s} d s\right]^{z} \log \left(1-\int_{s} \Psi(s) n(s) \gamma^{1} \frac{\nu^{i}}{s} d s\right)
$$

This is positive because the first term is negative as is the second because $1-\int_{s} \Psi(s) n(s) \gamma^{1} \frac{\nu^{i}}{s} d s<1$. Therefore $z^{\prime}>z \Rightarrow \rho^{i}\left(z^{\prime}\right) \geq \rho^{i}(z)$ for $i \in\{0,1\}$.

\subsection{Proof of Proposition 3}

The distribution of $z$ conditional on finding a job out of unemployment is given by the number of matches for any given $z,(1-n(z)) \Omega(z)\left(1-\gamma^{0}\right) \rho^{0}(z)(1-\tilde{G}(R(z)))$, divided by the total number of matches given by integrating over $z$. Thus, the distribution is $\frac{(1-n(z)) \Omega(z) \rho^{0}(z)(1-\tilde{G}(R(z)))}{\int(1-n(t)) \Omega(z) \rho^{0}(t)(1-\tilde{G}(R(t))) d t}$. We find the distribution of $z$ for direct-search matches analogously, $\frac{(1-n(z)) \Omega(z)(1-F(R(z)))}{\int(1-n(t)) \Omega(t)(1-F(R(t))) d t}$.

Using $\gamma^{0}=\gamma^{1}$, as in Lemma 1 , implies $R(z)=b \forall z$ and therefore $\underline{\mathrm{w}}=b$. Thus $(1-F(R(z))=$ $(1-\tilde{G}(R(z))=1$.

We show the network-search distribution first-order stochastically dominates the direct-search distribution by showing likelihood ratio dominance. Consider any $z, z^{\prime}$ such that $1<z<z^{\prime}<\infty$. Then the likelihood ratio given $z$ is

$$
\begin{aligned}
& \frac{(1-n(z)) \Omega(z) \rho^{0}(z)(1-\tilde{G}(R(z)))}{(1-n(z)) \Omega(z)(1-F(R(z)))} \frac{\int_{1}^{\infty}(1-n(t)) \Omega(t)(1-F(R(t))) d t}{(1-n(t)) \Omega(t) \rho^{0}(t)(1-\tilde{G}(R(t))) d t} \\
= & \rho^{0}(z) \frac{\int_{1}^{\infty}(1-n(t)) \Omega(t)(1-F(R(t))) d t}{(1-n(t)) \Omega(t) \rho^{0}(t)(1-\tilde{G}(R(t))) d t}
\end{aligned}
$$

And then

$$
\rho^{0}\left(z^{\prime}\right) \frac{\int_{1}^{\infty}(1-n(t)) \Omega(t)(1-F(R(t))) d t}{\int_{1}^{\infty}(1-n(t)) \Omega(t) \rho^{0}(t)(1-\tilde{G}(R(t))) d t} \geq \rho^{0}(z) \frac{\int_{1}^{\infty}(1-n(t)) \Omega(t)(1-F(R(t))) d t}{\int_{1}^{\infty}(1-n(t)) \Omega(t) \rho^{0}(t)(1-\tilde{G}(R(t))) d t}
$$

because the fractions, $\frac{\int_{1}^{\infty}(1-n(t)) \Omega(t)(1-F(R(t))) d t}{\int_{1}^{\infty}(1-n(t)) \Omega(t) \rho^{0}(t)(1-\tilde{G}(R(t))) d t}$ cancel and $\frac{\partial \rho^{0}(z)}{\partial z}>0$ implies $\rho^{0}\left(z^{\prime}\right) \geq \rho^{0}(z)$ iff $z^{\prime} \geq z$. Therefore, we have shown likelihood ratio dominance which also implies first order stochastic dominance.

\subsection{Sufficiency of the State}

In this section we first describe the equilibrium conditions for a similar economy to our main model, with a more general state space, in which the worker's position is not summarized simply by her number of peers, but rather by a complete description of the state of the social network. Let $\chi \in \mathbb{X}$ describe the worker's position in the network; literally a worker's state is her employment status and collection of peers, and their employment status and collection of peers, and so on. We will define $\chi$ recursively, as it is otherwise quite a cumbersome object. Consider an individual whose 
number of direct connections is $z \in[1, \infty)$, then $\chi$ is a $z \times 3$ object. $\chi$ contains, for each connection indexed $c \in \chi$ a triple, $(i(c), w(c), \chi(c))$ : The connection's employment status $i(c) \in\{0,1\}$, wage $w(c) \in \mathbb{W}$ and that connection's own position in the network $\chi(c)$. That is, worker knows their peers employment status, wage, and position in the network. We will call a worker's $\chi$ their "position," and continue, with a slight abuse of notation, to refer to the number of direct peers they have, $z$, as their "type."

With this notation we can re-define many of the objects of our model. Let $s(c)$ be the type of a worker whose position in the network is $c$; in general two workers who are both have type $s$ might have very different positions $c$, which depends on their employment status and position of their peers, and peer's peers, and so on. Then the rate of contact through one's network is:

$$
\rho^{i}(\chi)=\left(1-\prod_{c \in \chi}\left[1-n(c) \gamma^{1} \frac{\nu^{i}}{s(c)}\right]\right)
$$

That is, there is a probability particular peer has a chance to pass a job, which depends on her employment status and precise position in the network, and the chance that at least one peer does so is given by $\rho^{i}(\chi) \cdot{ }^{13}$

Given $F, G, n$ and the $\left\{\rho^{0}(\chi), \rho^{1}(\chi)\right\}$ implied by Equations $6-8$, the household value functions solve

$$
\begin{aligned}
r V^{0}(\chi) & =b+\gamma \int_{R(\chi)}^{\bar{w}} V^{1}(\chi, x)-V^{0}(\chi) d F(x) \\
& +\left(1-\gamma^{0}\right) \rho^{0}(\chi) \int_{c \in \chi}\left(V^{1}(\chi, w(c))-V^{0}(\chi)\right) \mathbb{I}_{w(c) \geq R(\chi)} d c \\
r V^{1}(\chi, w) & =w+\delta\left[V^{0}(\chi)-V^{1}(\chi, w)\right]+\gamma^{1} \int_{w}^{\bar{w}} V^{1}(\chi, w)-V^{0}(\chi) d F(x) \\
& +\left(1-\gamma^{1}\right) \rho^{1}(\chi) \int_{c \in \chi}\left(V^{1}(\chi, x(c))-V^{0}(\chi)\right) \mathbb{I}_{w(c) \geq w} d c \\
R(\chi) & =b+\left(\gamma^{0}-\gamma^{1}\right) \int_{R(\chi)}^{\bar{w}} V^{1}(\chi, x)-V^{0}(\chi) d F(x) \\
& +\left(\rho^{0}(\chi)-\rho^{1}(\chi)\right) \int_{c \in \chi}\left(V^{1}(w(c), \chi)-V^{0}(\chi)\right) \mathbb{I}_{w(c) \geq R(\chi)} d c
\end{aligned}
$$

Note that the integrations in these value functions are over the known positions of each peer; the only uncertainty is in the friction of the wage transmission procedure, not in the positions of peers. The steady state earnings distribution and employment probabilities for a worker of position $\chi$ are

\footnotetext{
${ }^{13}$ In this case, the worker with complete information still receives only one job at random in the event that multiple jobs offers are passed to him; she cannot choose, for example, the highest wage offer, even though she knows which peer has the highest wage. We interpret this as a remaining friction in the labor market, even with complete information on the state. One can imagine alternative offer selection procedures, but this would change the wage dynamics drastically from our baseline model, and are not pursued here.
} 
given by

$$
\begin{aligned}
n(\chi) & =\frac{\gamma^{0}(1-F(R(\chi)))+\left(1-\gamma^{0}\right) \rho^{0}(\chi)}{\delta+\gamma^{0}[1-F(R(\chi))]+\left(1-\gamma^{0}\right) \rho^{0}(\chi)} \\
G(w, \chi) & =\frac{(1-n(\chi))\left\{\gamma^{0}[F(w)-F(R(\chi))]+\left(1-\gamma^{0}\right) \rho^{0}(\chi)\right\}}{n(\chi)\left\{\delta+\gamma^{1}[1-F(w)]+\left(1-\gamma^{1}\right) \rho^{1}(\chi)\right\}}
\end{aligned}
$$

Definition of General Recursive Equilibrium: An equilibrium in this economy is the searcher's value function $V^{0}: \mathbb{X} \rightarrow \mathbb{R}$, worker's value function $V^{1}: \mathbb{X} \times \mathbb{W} \rightarrow \mathbb{R}$ corresponding policy functions - reservation wages - $R: \mathbb{X} \rightarrow \mathbb{W}$, a level of profit at each wage, $\pi: \mathbb{W} \rightarrow \mathbb{R}_{+}$, a distribution of posted wage offers $F: \mathbb{W} \rightarrow[0,1]$, distributions of worker's wages, $G: \mathbb{W} \times$ $\mathbb{X} \rightarrow[0,1]$, employment rate $n: \mathbb{X} \rightarrow[0,1] . V^{1}, V^{0}$ satisfy Equations 31 and $32, R^{0}$ satisfies

equation 33, $G$ and $n$ are consistent with Equations 35 and 34 given an $F$ which implies that $\pi(\chi, w)=\bar{\pi} \forall w \in \mathbb{W}$.

\subsubsection{Limited Information}

We now consider the worker's problem when she has limited information on the status of her peers; we will show that the mean-field approach adopted above is precisely the result of a more general model with limited information and a particular network topology. First, we impose the requirement that workers no longer know their positions in the network, nor their type, their employment status, or their wages; we further assume she has no memory of past wage offers received, or who passed them. All she knows is the global structure of the network and her own type $z$-but not her true position in the network, $\chi$, for this would imply the position of all her peers. Thus, there may be many different positions $\chi$ consistent with her information - she cannot know which of the many $\chi$ such that $z \in \chi$ correctly describes her position. Since he knows the global network structure, he knows all the possible $\chi$ that may describe her position, and how likely they are, and may form an expectation of the value of a wage passed by a peer.

Let our worker's belief over her own true network position $\chi$, given her information, which is her type $z$, be $\operatorname{Pr}(\chi \mid z)$. For an arbitrary complex, large, network, this could be a very complicated object, or very simple; there might me finitely many $\chi$ consistent with $z$, or infinitely many. The various positions $\chi$ consistent with $z$ might vary widely in the value of their peer, so that network search is risky provides less value, or they might all be very similar. Note that this belief is over $\chi$, and so includes beliefs over employment status and wage, which in equilibrium must be consistent. In this framework, the probability a worker is passed a job is given by

$$
\rho^{i}(z)=\left(1-\left[1-\int_{s} n(s) \gamma^{1} \frac{\nu^{i}}{s} \Psi(s) d s\right]^{z}\right)
$$


This worker can no longer use her position to calculate precise probabilities he is passed a job from a particular peer, because each peer is, from her point of view identical, with a unknown number of other peers who compete for her job information. Let the unknown position of a particular peer of this worker be called $\kappa$; the type of this worker is $s$, and these are both unknown, but may be inferred from $\chi$, and will have distributions $\operatorname{Pr}(s \mid \chi), \operatorname{Pr}(\kappa \mid s, \chi)$. Let the wage of a peer of type $s$ and position $\kappa$ be $w(s, \kappa)$.

The value function of the household can therefore be written

$$
\begin{aligned}
& r V^{0}(z)=b+\gamma^{0} \int_{R(\chi)}^{\bar{w}}\left(V^{1}(z, x)-V^{0}(z)\right) d F(x)+ \\
& \left(1-\gamma^{0}\right) \rho^{0}(z) \int_{\chi}\left[\int_{s}\left[\int_{\kappa}\left(V^{1}(z, w(s, \kappa))-V^{0}(\chi)\right) \operatorname{Pr}(\kappa \mid s, \chi) d \kappa\right] \operatorname{Pr}(s \mid \chi) d s\right] \operatorname{Pr}(\chi \mid z) d \chi
\end{aligned}
$$

Note that this implies that any two workers with the same type $z$ will have the same beliefs, in equilibrium, and a worker's type $z$ is a sufficient statistic for her position $\chi$. Policy functions therefore cannot be functions of $\chi$, but only of $z$. A the wage passed by a peer, however, may depend on the actual network position $\chi$, however; even if that worker's choices cannot be functions of $\chi$, the actually realized wages passed may be. Thus beliefs over $\chi$ will influence the value of network search. The precise form those beliefs must take, however, depends on the global structure of the network.

\subsubsection{Local Structure of the Network}

Under the topology generated by the Chung-Lu procedure, the resulting network is locally tree-like; in the limit as the number of nodes $n->\infty$, the probability of a loop forming, and in particular the probability of a local cluster forming, vanish on the order of $O\left(\frac{1}{n}\right)$. There are no correlations between worker types, and starting from any two nodes of type $z$, they network structure can be described as a random branching process, where each subsequent node's own degree $s$ is drawn from the distribution of peers types $\Psi(s)$. Thus, a worker's position $\chi$, given a worker's type $z$, is a realization of $z$ independent, identically distributed branching processes, with offspring distribution $\Psi$; because the network is infinitely large, there is a position $\chi$ in the network corresponding to every possible realization of these branching processes, which a worker must average over to form her expected value of network search. This implies that the probability a worker's local network structure deviates from the mean realization of the collection of branching processes - that is, the probability that her position $\chi$ is either much more or much less valuable than the position of another worker's, who is of the same type $z$-is zero. Under this procedure, therefore, 


$$
\operatorname{Pr}(s \mid \chi)=\Psi(s)
$$

That is, the probability that a worker's peer has degree $s$ is independent of the network position $\chi$ of the worker, and is given by the offspring distribution $\Psi$. Second,

$$
\operatorname{Pr}(\kappa \mid s, \chi)=\operatorname{Pr}(\kappa \mid s)
$$

The distribution over a peer's position $\kappa$ is independent of $\chi$; with probability 1 all peers of type $s$ have the same network distribution over positions $\kappa$, regardless of $\chi$.

The distribution over a worker's peer's higher order peers - and their employment status and wages - is independent of that worker's position in the network, and that peer's degree $s$. Under our informational assumptions, because workers cannot condition on their global position in the network but only over their own type.

$$
\begin{aligned}
& \int_{\chi}\left[\int_{s}\left[\int_{\kappa} V^{i}(z, w(s, \kappa)) \operatorname{Pr}(\kappa \mid s, \chi) d \kappa\right] \operatorname{Pr}(s \mid \chi) d s\right] \operatorname{Pr}(\chi \mid z) d \chi \\
& =\int_{\chi}\left[\int_{s}\left[\int_{\kappa} V^{i}(z, w(s, \kappa)) \operatorname{Pr}(\kappa \mid s) d \kappa\right] \Psi(s) d s\right] \operatorname{Pr}(\chi \mid z) d \chi \\
& =\int_{s}\left[\int_{\kappa} V^{i}(z, w(s, \kappa)) \operatorname{Pr}(\kappa \mid s) d \kappa\right] \Psi(s) d s \times \int_{\chi} \operatorname{Pr}(\chi \mid z) d \chi \\
& =\int_{s}\left[\int_{\kappa} V^{i}(z, w(s, \kappa)) \operatorname{Pr}(\kappa \mid s) d \kappa\right] \Psi(s) d s \times 1 \\
& =\int_{s}\left[\int_{\kappa} V^{i}(z, w(s, \kappa)) \operatorname{Pr}(\kappa \mid s) d \kappa\right] \Psi(s) d s .
\end{aligned}
$$

It remains only to show that the expected value of a wage passed in this network is equal to the value of the expected wage, as in section 2 ; that is, to show that there is no risk associated with the unknown network position of a peer, $\kappa$. For a general network, there may be; it could be that some network positions consistent with $z$ are advantageous - in that the degree and wages of their neighbors are high — and other less so. This possibility is eliminated under the Chung-Lu topology. Under this network structure, there are infinitely many positions $\chi$ consistent with $z$, that each correspond to a possible realization of collection of branching processes. A law of large numbers results guarantees that the expected wage of a random peer is almost surely the average wage. Let us define

$$
w(s)=\int_{\kappa} w(s, \kappa) \operatorname{Pr}(\kappa \mid s) d \kappa
$$

to be the expected wage of a worker of type $s$, averaging over all the various $\kappa$ they may have. Under the Chung-Lu topology, the probability the wage of a peer of type $s$ deviates from this wage 
is zero. Thus, the probability

$$
\operatorname{Pr}\left(\left|V^{i}(z, w(s, \kappa))-V^{i}(z, w(s))\right|>\delta\right)
$$

for any $\delta>0$ vanishes as the network size grows according to the Chung-Lu procedure. Thus we can write equation 39 as

$$
\int_{s} V^{i}(z, w(s)) \Psi(s) d s
$$

just as in section 2. Under this interpretation, the wage function $w(s)$ we solve for in the section 3 is the expected wage of a worker with $s$ peers, averaging over all the different higher order peers $\kappa$ he may have; some such peers of type $s$ may be unlucky enough to have poorly connected peers, and even though this worker uses the same policy functions as another worker with $s$ peers, her wage will be lower. Another, more lucky, worker of type $s$ may, despite using the same policy functions as every other worker of type $s$, have a higher equilibrium wage, because her well connected peers pass him an unusually high number of good jobs. Such outcomes are happen with probability zero under the Chung-Lu topology. Thus a worker can ignore this possibility when forming a belief over the value of a wage passed by a peer of type $s$, and us only the average wage of these peers, $w(s)$. This is precisely the mean field approach.

\section{References}

Bayer, P., S. L. Ross, And G. TopA (2008): "Place of Work and Place of Residence: Informal Hiring Networks and Labor Market Outcomes," Journal of Political Economy, 116, 1150-1196.

Bender, E. A. And E. CANFiEld (1978): "The asymptotic number of labeled graphs with given degree sequences," Journal of Combinatorial Theory, Series A, 24, 296 - 307.

Bentolila, S., C. Michelacci, And J. Suarez (2010): "Social Contacts and Occupational Choice," Economica, 77, 20-45.

Bontemps, C., J.-M. Robin, And G. J. van Den Berg (2000): "Equilibrium Search with Continuous Productivity Dispersion: Theory and Nonparametric Estimation," International Economic Review, 41, 305-58.

Brown, M., E. Setren, And G. Topa (2013): "Do informal referrals lead to better matches? Evidence from a firm's employee referral system," Staff Reports 568, Federal Reserve Bank of New York.

Burdett, K. And D. T. Mortensen (1998): "Wage Differentials, Employer Size, and Unemployment," International Economic Review, 39, 257-73. 
Burks, S., B. Cowgill, M. Hoffman, And M. Housman (2015): "The Value of Hiring through Employee Referrals," The Quarterly Journal of Economics, 130, 805-839.

Calvo-Armengol, A. And M. O. Jackson (2004): "The Effects of Social Networks on Employment and Inequality," American Economic Review, 94, 426-454.

- (2007): "Networks in labor markets: Wage and employment dynamics and inequality," Journal of Economic Theory, 132, 27-46.

Cappellari, L. And K. Tatsiramos (2015): "With a little help from my friends? Quality of social networks, job finding and job match quality," European Economic Review, 78, 55-75.

Chung, F. And L. Lu (2002): "Connected Components in Random Graphs with Given Expected Degree Sequences," Annals of Combinatorics, 6, 125-145.

Cingano, F. And A. Rosolia (2012): "People I Know: Job Search and Social Networks," Journal of Labor Economics, 30, 291 - 332.

DAtcher, L. (1983): "The Impact of Informal Networks of Quit Behavior," The Review of Economics and Statistics, 65, 491-95.

Dustmann, C., A. Glitz, And U. Schonberg (2015): "Referral-based Job Search Networks," The Review of Economic Studies, forthcoming.

FELD, S. L. (1991): "Why Your Friends Have More Friends Than You Do," American Journal of Sociology, 96, 1464-1477.

Fontaine, F. (2008): "Why are similar workers paid differently? the role of social networks," Journal of Economic Dynamics and Control, 32, 3960-3977.

Gabaix, X. (2008): "Power Laws in Economics and Finance," Working Paper 14299, National Bureau of Economic Research.

Galenianos, M. (2014): "Hiring through referrals," Journal of Economic Theory, 152, 304-323. (2016): "Referral Networks and Inequality," 2016 meeting papers, Society for Economic Dynamics.

Glitz, A. (2013): "Coworker Networks in the Labour Market," IZA Discussion Papers 7392, Institute for the Study of Labor (IZA).

Granovetter, M. (1995): Getting a Job: A Study of Contacts and Careers, Chicago, IL, USA: 2nd ed., University of Chicago Press. 
Hellerstein, J. K., M. J. Kutzbach, and D. Neumark (2015): "Labor Market Networks and Recovery from Mass Layoffs Before, During, and After the Great Recession," Working Paper 21262, National Bureau of Economic Research.

Hellerstein, J. K., M. McInerney, And D. Neumark (2011): "Neighbors and Coworkers: The Importance of Residential Labor Market Networks," Journal of Labor Economics, 29, 659 -695 .

Holzer, H. (1988): "Search Method Use by Unemployed Youth," Journal of Labor Economics, $6,1-20$.

Hornstein, A., P. Krusell, And G. L. Violante (2011): "Frictional Wage Dispersion in Search Models: A Quantitative Assessment," American Economic Review, 101, 2873-98.

IoAnnides, Y. M. And L. DATCher Loury (2004): “Job Information Networks, Neighborhood Effects, and Inequality," Journal of Economic Literature, 42, 1056-1093.

IoAnnides, Y. M. And A. R. Soetevent (2006): "Wages and Employment in a Random Social Network with Arbitrary Degree Distribution," American Economic Review, 96, 270-274.

Kugler, A. (2003): "Employee referrals and efficiency wages," Labour Economics, 10, 531-556.

Marmaros, D. And B. Sacerdote (2002): "Peer and social networks in job search," European Economic Review, 46, 870-879.

Montgomery, J. D. (1991): "Social Networks and Labor-Market Outcomes: Toward an Economic Analysis," American Economic Review, 81, 1407-18.

Mortensen, D. T. And C. A. Pissarides (1999): "New developments in models of search in the labor market," in Handbook of Labor Economics, ed. by O. Ashenfelter and D. Card, Elsevier, vol. 3 of Handbook of Labor Economics, chap. 39, 2567-2627.

Mortensen, D. T. And T. Vishwanath (1994): "Personal contacts and earnings : It is who you know!" Labour Economics, 1, 187-201.

Newman, M. E. J. (2004): "Coauthorship networks and patterns of scientific collaboration," Proceedings of the National Academy of Sciences, 101, 5200-5205.

Pissarides, C. A. (2000): Equilibrium Unemployment Theory, 2nd Edition, vol. 1 of MIT Press Books, The MIT Press.

Postel-Vinay, F. And J.-M. Robin (2002): "Equilibrium Wage Dispersion with Worker and Employer Heterogeneity," Econometrica, 70, 2295-2350. 
Simon, C. J. And J. T. WARner (1992): "Matchmaker, Matchmaker: The Effect of Old Boy Networks on Job Match Quality, Earnings, and Tenure," Journal of Labor Economics, 10, 30630.

TopA, G. (2011): "Chapter 22 - Labor Markets and Referrals," North-Holland, vol. 1 of Handbook of Social Economics, 1193 - 1221.

Ugander, J., B. Karrer, L. Backstrom, and C. Marlow (2011): "The Anatomy of the Facebook Social Graph," CoRR, abs/1111.4503.

VAn den BerG, G. J. And G. Ridder (1998): "An Empirical Equilibrium Search Model of the Labor Market," Econometrica, 66, 1183-1222.

Vega-Redondo, F. (2007): Complex social networks, 44, Cambridge University Press. 